\title{
Assessment and Prediction of Groundwater using Geospatial and ANN modeling
}

Ankita Pran Dadhich ( $\nabla$ ankitadadhich@mnit.ac.in )

Malaviya National Institute of Technology

\section{Rohit Goyal}

Malaviya National Institute of Technology

\section{Pran Nath Dadhich}

Poornima Institute of Engineering and Technology

\section{Research Article}

Keywords: Groundwater, ARIMA, Artificial neural network, Water quality, Geospatial, Phagi

Posted Date: April 15th, 2021

DOl: https://doi.org/10.21203/rs.3.rs-246464/v1

License: (1) This work is licensed under a Creative Commons Attribution 4.0 International License. Read Full License 


\title{
Assessment and Prediction of Groundwater using Geospatial and ANN modeling
}

\author{
Ankita P. Dadhich ${ }^{1}$, Rohit Goyal ${ }^{1}$, Pran N. Dadhich ${ }^{2}$ \\ ${ }^{1}$ Department of Civil Engineering, Malaviya National Institute of Technology, J.L.N. Marg, \\ Jaipur 302017, (Rajasthan) INDIA \\ ${ }^{2}$ Department of Civil Engineering, Poornima Institute of Engineering \& Technology, ISI-2, \\ RIICO Institutional Area, Sitapura, Jaipur 302022 (Rajasthan), INDIA \\ Email:ankitadadhich@mnit.ac.in,rgoyal.ce@mnit.ac.in,pran.dadhich@poornima.org
}

\begin{abstract}
In semi-arid regions the deterioration in groundwater quality and drop in water level upshots the importance of spatio-temporal mapping with geospatial and advanced modeling techniques. In present study, changes in water level, water quality trend patterns and future scenarios of groundwater in 171 villages of Phagi tehsil, Jaipur district was assessed using eight years (2012-2019) groundwater data. Spatial interpolation maps were drawn using kriging method for pre-monsoon season and integrated with three different time series forecasting models (Simple Exponential Smoothing, Holt's Trend Method, ARIMA) and Artificial Neural Network models to ascertain the optimal prediction for groundwater level and quality parameters. Results reveal that the use of ANN model can describe the behavior of groundwater level and quality parameters more accurately than time series forecasting models. In addition, different ANN algorithms were tested to select the best-performing algorithm and ANN15 is found the most accurate one in simulating the magnitude and patterns of pre-monsoon water level data for year 2019 with $\mathrm{R}^{2}=0.98$, and NSE $=0.81$. The change in groundwater table was observed with more than 4.0m rise in 81 villages during 2012-2013 whereas ANNpredicted results of
\end{abstract}


2023-2024 infer no rise in water table $(>4.0 \mathrm{~m})$. Water level drop of more than $6.0 \mathrm{~m}$ was observed in 16 villages of Phagi tehsil based on predicted results of 2024. Assessment of groundwater quality parameters like Total dissolved solids, chloride, fluoride and nitrate indicate chemically unsuitable groundwater for drinking purpose in most part of the Phagi. ANNpredictions point out excess nitrate content in 58\% villages however, Water quality Index reveals unfit groundwater in $74 \%$ villages for human consumption in 2024 . This time series and projected outcome of groundwater at village level can assist the planners and decisionmakers for proper management of groundwater risk areas.

\section{Keywords- Groundwater; ARIMA; Artificial neural network; Water quality; Geospatial; Phagi}

\section{Introduction}

In arid and semi-arid environment where rainfall is scanty and highly variable with very high evaporation rate; groundwater is the vital local source for drinking, agricultural, industrial and domestic uses. Groundwater is generally considered better than surface water because of its higher quality, less evapo-transpiration and less susceptible to contamination (Chenini and Ben 2010; Kumar et al. 2016). In the last few decades, the availability of ground water is at a greater risk in Rajasthan state of India due to growing population, urbanization, and large quantities of groundwater withdrawal for crop production. Over-exploitation of groundwater resources and drought events have caused severe drop in water table level of Rajasthan. Acute water crisis could be observed in many parts of Rajasthan especially during the summer months. The variations in the groundwater level reflects the impact of climatic condition, groundwater consumption, water storage and other human activities (Minville et al. 2010; Ghazavi et al. 
2012); hence groundwater level fluctuation is an important indicator of the ecology and hydrology of the arid region (Jolly et al. 2008).

The groundwater quality of a region worsens due to geochemical reactions in the aquifers/soils during its transportation through canals/drainages, and excessive use of chemical fertilizers and pesticides (Singh et al. 2013; Rawat et al. 2018). The use of such contaminated water may lead to variety of water borne diseases, hence periodic monitoring and assessment of groundwater resources becomes necessary to determine the impact of human activities on groundwater deterioration (Gautam et al. 2018).

In areas with shortage of surface waterbodies, development of different management strategies for groundwater resource is emerging as an area of great concern in recent decades. Geospatial technique can be the powerful tool for finding the solutions related to groundwater resources problems such as determining water availability, rise and drop in water level, assessing water quality, monitoring, modeling, estimation of the contaminant concentrations in locations that lack measurement data (Gharbia et al. 2016) and efficient use of groundwater resources at local or regional scale (Srivastava et al. 2012; Verma et al. 2017). Apart from this the detailed spatial and temporal trend patterns of groundwater quality and quantity over a certain period of time using geospatial techniques, could provide reliable, efficient, cost effective and sustainable management measures. With the availability of soft computing techniques, different models could be adopted to understand the scenarios of groundwater for both quantity and quality (Nas and Berktay 2010; Charulatha et al. 2017).

Few research studies (Yesilnacar et al. 2008; Mohanty et al. 2010; Sunayana et al. 2019) suggest that neural network models could help in predicting the groundwater quality and groundwater level well in advance for understanding the future scenario. Artificial neural network (ANN) models have also been applied to the water quality problems by several researchers (Singh et al. 2009; Ay and Kisi 2012; Csábrági et al. 2017). Present study is 
confined to semi-arid rural region (Phagi tehsil) of Jaipur district in Rajasthan state. In Phagi tehsil most of the population is dependent on groundwater for their domestic and agriculture needs. The groundwater quality of the study area is under stress of severe pollution (Singh et al.2012; Sharma et al. 2015), hence deterioration in groundwater quality and drop in water level marks the importance of spatio-temporal mapping with geospatial interpolation technique. Geospatial technique can evaluate the groundwater risk areas of a region even with the availability of limited sample points (measured data). Therefore, it is imperative to understand the water quality trend patterns, changes in groundwater level and future scenarios of groundwater quality and quantity in Phagi tehsil. The aim of this research is: 1) to ascertain the spatial and temporal variations in the groundwater level and groundwater quality of Phagi tehsil during last 8 years (2012 to 2019) by developing spatial interpolation maps; 2) modeling of water level and important water quality parameters using time series forecasting \& ANN models and identification of optimum model based on model validation using historic data; 3) to predict the groundwater level changes and groundwater quality during 2019 to 2024 using the best forcasting model identified for understanding the variations with space and time at village level.

\section{Material and Methods}

\subsection{Study Area}

Phagi Tehsil is located in Jaipur district of Rajasthan state. It covers geographical area of $1,114.3 \mathrm{~km}^{2}$ and extending between north latitudes $26^{\circ} 25^{\prime}$ and $26^{\circ} 50^{\prime}$ and east longitudes $75^{\circ}$ $20^{\prime}$ and $75^{\circ} 50^{\prime}$ and forms south western part of the Jaipur District. According to 2011 Census, there are 32 gram panchayat, 22,713 households with total population of 161,610 and 145 per $\mathrm{km}^{2}$ population density. The average elevation of study area is $383 \mathrm{~m}$ and drained by two ephemeral rivers viz. Bandi river and Mashi river (Fig. 1). Geomorphologically, Phagi tehsil is 


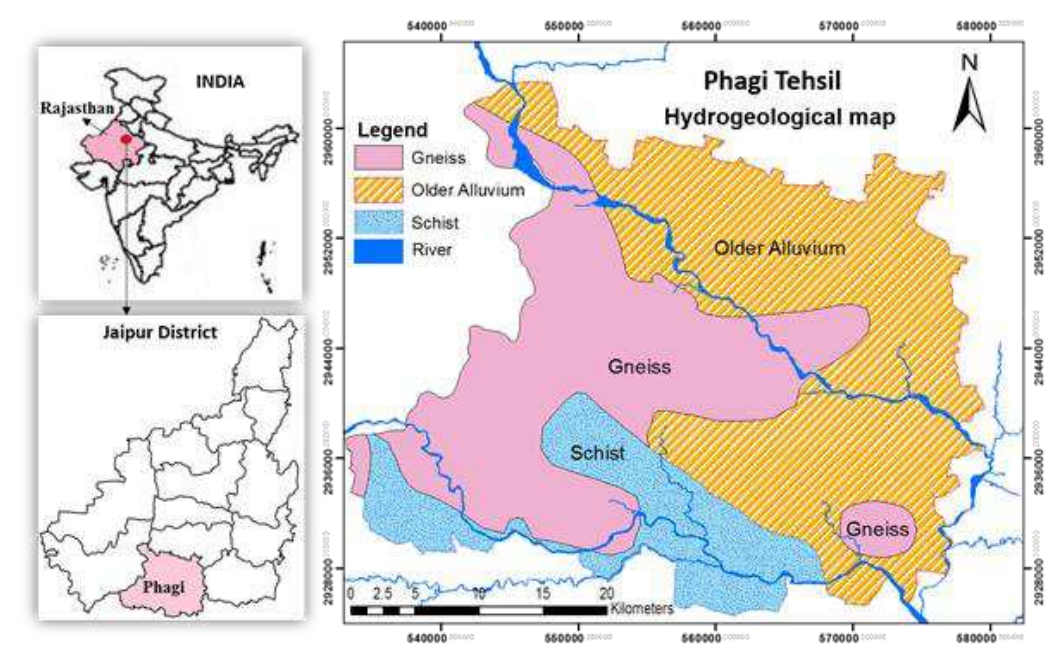

Fig. 1 Location and Hydrogeology of the study area

characterized by undulating plains and pediments with thin to thick soil cover forming flat gneissic outcrops. The climate of Phagi is semi arid and temperatures vary from 5 to $48^{\circ}$ Celsius. More than $90 \%$ annual rainfall is received during monsoon season. Annual average rainfall during the period 2005 to 2019 has been 539.89mm (Fig. 2a) in Phagi tehsil. The depth of groundwater varies from 3 to $45 \mathrm{~m}$ below ground level (bgl) in study area.

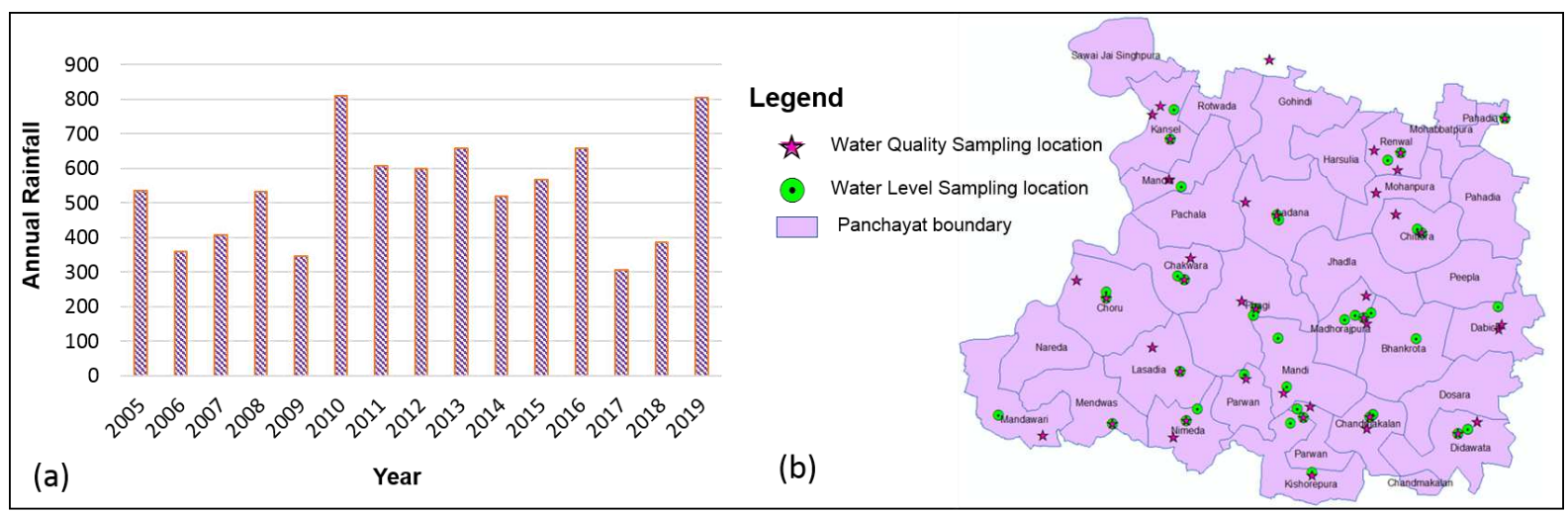

Fig. 2 (a) Variations in annual rainfall (2005-2019) source: Central Ground Water Board, Jaipur (b) Sampling locations in Phagi Tehsil

\subsubsection{Hydrogeology of the study area}

Fig. 1 shows the hydrogeology of the Phagi tehsil. Gneisses and schists of Bhilwara Super Group are the oldest rock types. Hard rocks of Bhilwara Super Group, comprising of granulitic 
gneisses, quartz, mica, schist, phyllite along with granite and pegmatite intrusives, form main aquifers in Phagi tehsil. Groundwater at shallow depth occurs under water table condition and under semi-confined conditions at depth (CGWB 2017).

\subsection{Data Collection}

The pre-monsoon data was collected for groundwater level and groundwater quality from State Ground Water Department (SGWD), Jaipur during 2012 to 2019 for different sampling locations (Fig. 2b) within the Phagi tehsil. The source of all the water level sampling locations was dug wells and piezometric wells however, water quality samples were collected from hand pumps, bore well and wells. The sampling locations were plotted in GIS environment using World Geodetic System (WGS) 1984 as datum and Universal Transverse Mercator (UTM) Zone 43 North as projection system. Table 1 and 2 shows the groundwater level and groundwater quality variations respectively in Phagi tehsil during the study period. Base maps such as district, tehsil, panchayat and village boundary along with the main rivers and hydrogeology of the study area were generated using ArcGIS.

Table 1 Groundwater level variations (2012-2019) in the study area

Table 2 Ground water Quality variations (2012-2019) in the study area

\subsection{Data Analysis}

\subsubsection{Spatial Interpolation through Kriging}

In present study, spatial analyst tool is applied for analyzing spatial and temporal trends of groundwater level and groundwater quality to achieve a better picture of the behavior of aquifer system over a long period for 171 villages of Phagi tehsil. Multiple year data of pre-monsoon season was used because normally the groundwater quality is worst during this period. 
Ordinary kriging technique was applied to describe and model spatial patterns, predict values at unmeasured locations, and assess the uncertainty associated with a predicted value. Kriging can be seen as an unbiased point interpolation method, which requires a point map as input and returns a raster map with estimations. Kriging is known to be an exact estimator because observation points are correctly re-estimated (Marsily, 1986; Journel, 1989). The advantage of Kriging above inverse distance weighted (IDW) method is that it provides a measure of the probable error associated with the estimates. The estimated or predicted values $(Z)$ is thus a linear combination known input point values $\left(\mathrm{z}_{\mathrm{i}}\right)$ and have a minimum estimation error. Thus,

$$
Z=\sum\left(W_{i} * Z_{i}\right)
$$

where, $\mathrm{W}_{\mathrm{i}}=$ weight factors.

In case the value of an output pixel would only depend on three input points, so:

$$
Z=W_{1} * Z_{1}+W_{2} * Z_{2}+W_{3} * Z_{3}
$$

Hence, to calculate one output pixel value $\mathrm{Z}$, three weight factors $\mathrm{W}_{1}, \mathrm{~W}_{2}, \mathrm{~W}_{3}$ have to be found for each input point value $Z_{1}, Z_{2}, Z_{3}$ then, multiply these weight factors with the corresponding input point values. Weight factors can be calculated by finding the semi-variance values for all distances between input points and by finding semi-variance values for all distances between an output pixel and all input points. Several researchers (Ahmadi and Sedghamiz 2007; Ta'any et al. 2009; Nayak et al. 2015) applied Ordinary Kriging for groundwater level values interpolation. In this study ordinary kriging method is used with spherical semi-variogram model. The benefit of ordinary kriging is that one can influence the number of points that should be taken into account in the calculation of an output pixel value by specifying a limiting distance and a minimum and maximum number of points (Nayak et al. 2015).

Fig. 3 shows the contour map of the water table level in pre-monsoon season from 2012 to 2019. Trend shows that the watertable level in northern and eastern parts of the Phagi tehsil area is deeper than the other parts of the study area. The groundwater quality data was also 


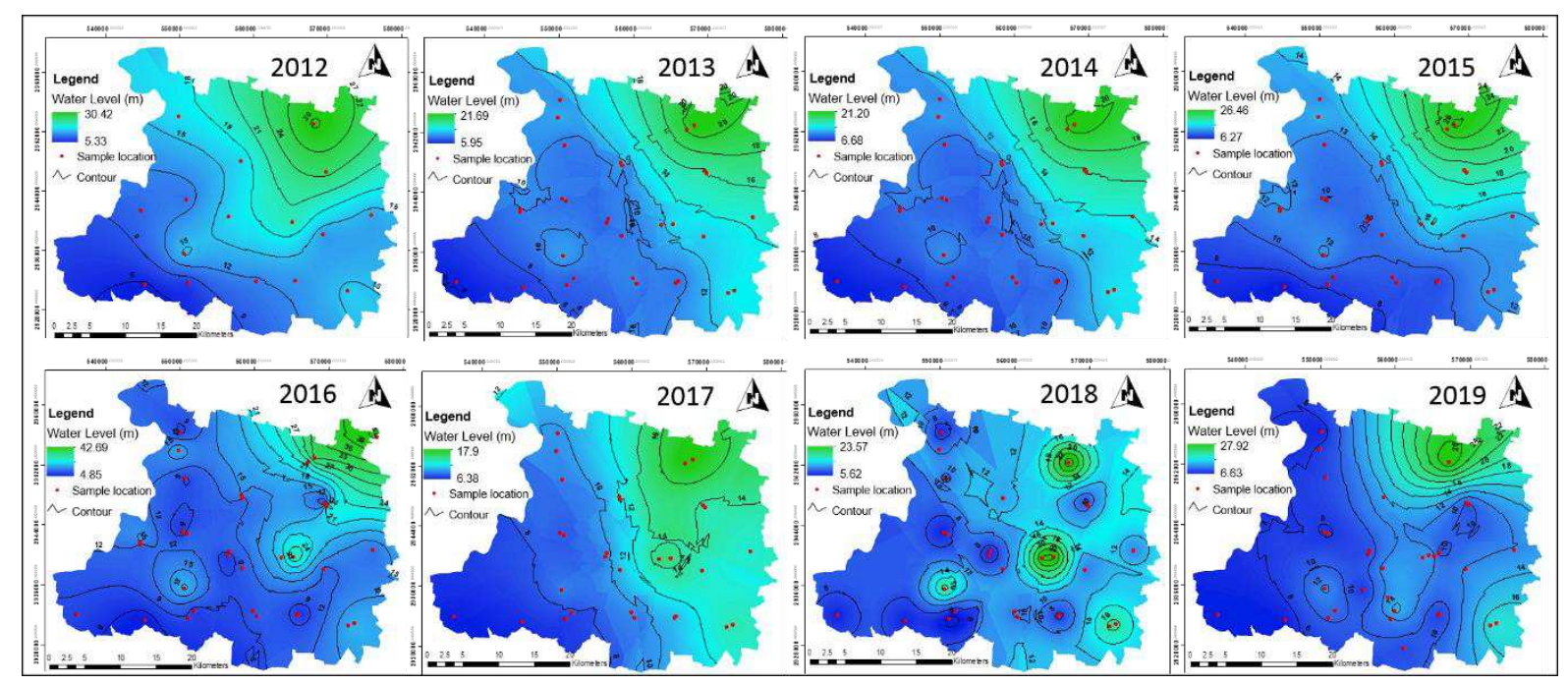

Fig. 3 Spatial and temporal variability in groundwater level during 2012-2019 (pre-monsoon)

interpolated using ordinary kriging method for the study period. Four important water quality parameters such as TDS, Fluoride, Nitrate and Chloride were interpolated at village level and it reflects (Fig. 4) that the groundwater quality of Phagi tehsil is deteriorating.

\subsubsection{Zonal Statistics}

Zonal analysis is an important raster based analysis tool in ArcGIS and used for different GIS related studies viz. demographic studies, surface modelling, environmental monitoring, planning and design, land management etc. (Ratti and Richens 2004; Dadhich and Hanaoka 2010; Measho et al. 2019). Zonal statistics tool creates an output raster or statistics table from the input value raster that intersect or fall within each zone of a specified input zone dataset. A single output value is computed for every zone in the input zone dataset. In present study zonal statistics tool is used to create groundwater quality and groundwater level at village level for Phagi tehsil from interpolated raster layers. Fig. 4 shows the temporal changes (2012 to 2019) in selected water quality parameters at village level for pre-monsoon season. 


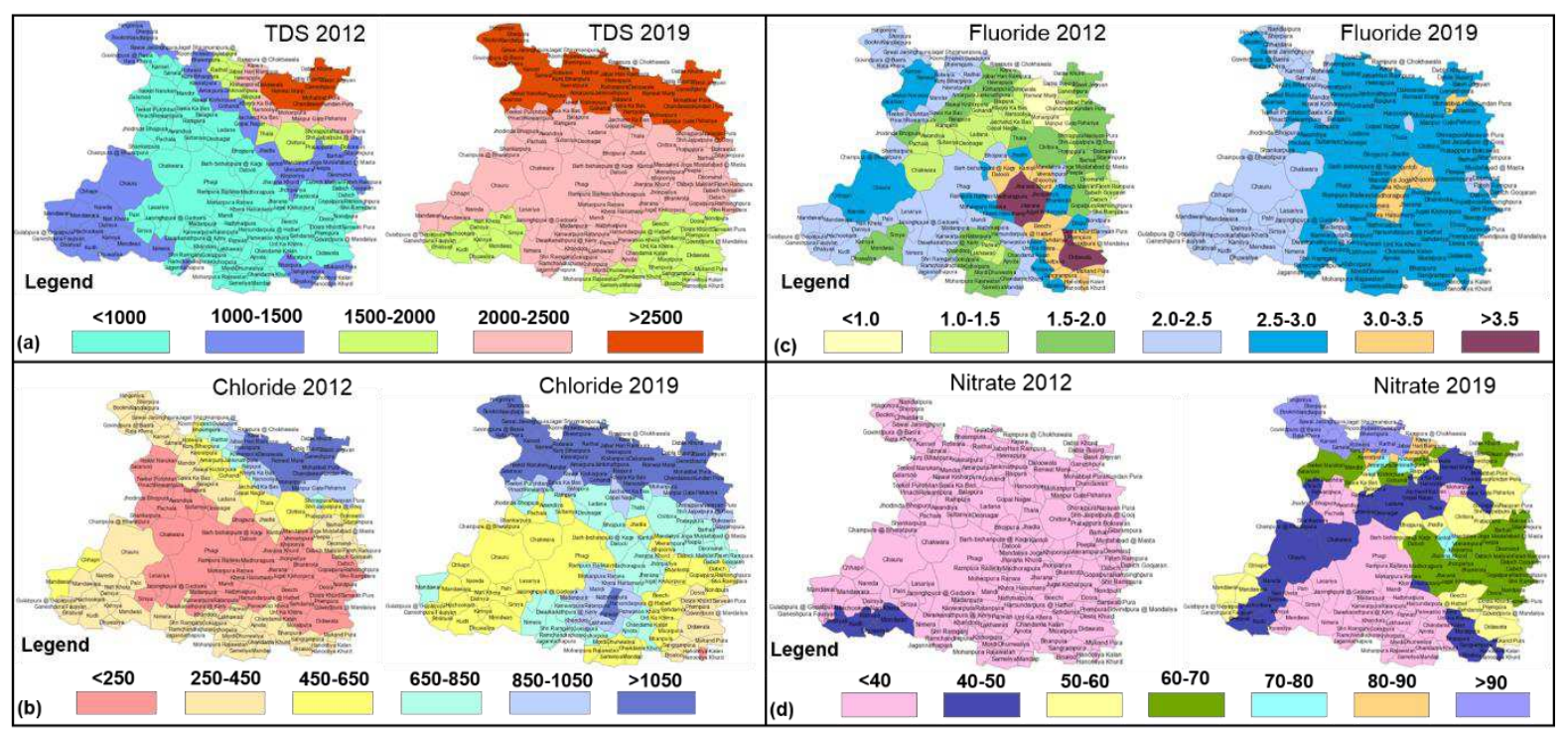

Fig. 4 Temporal changes in groundwater quality (in mg/l) from 2012 to 2019

\subsubsection{Time series forecasting}

Time series analysis is an essential tool for better forecasts in hydrology studies (Bărbulescu 2016). In this study different time series forecasting techniques like Simple Exponential Smoothing (SES), Holt's Trend Method (HTM) and ARIMA were applied using the statistical programming language 'R' (Hyndman et al. 2017). Package in $r$ language includes most of the methods based on exponential smoothing or AutoRegressive Integrated Moving Average (ARIMA) and related stochastic processes.

In SES method forecasts are produced using weighted averages of past observations, with the weights decaying exponentially as the observations get older. In other words, higher weights are given to the more recent observations and vice versa. The basic equation (Brown and Robert G. 1956) is represented by ' $y$ ' beginning at time $t=0$, and the output of the exponential smoothing algorithm is written as ' $S_{t}$ ', which may be regarded as a best estimate of what the next value of ' $y$ ' will be. Equation is expressed as:

$$
S_{t}=\alpha y_{t-1}+(1-\alpha) S_{t-1}
$$


where, $\alpha=$ the smoothing constant, varies from 0 to 1 . When $\alpha$ is close to zero, smoothing happens slowly, and $t=$ time period. However, HTM method considers the trend component while generating forecasts. This method involves two smoothing equations, one for the level and another one for the trend component. Holt (1957) extended simple exponential smoothing to allow the forecasting of data with a trend.

$$
\begin{aligned}
& \text { Forecast equation } \hat{\mathrm{y}}_{\mathrm{t}+\mathrm{h} \mid \mathrm{t}}=\ell_{t}+\mathrm{hb}_{t} \\
& \text { Level equation } \ell_{t}=\alpha \mathrm{y}_{t}+(1-\alpha)\left(\ell_{t-1}+\mathrm{b}_{t-1}\right) \\
& \text { Trend equation } \mathrm{b}_{t}=\beta *\left(\ell_{t}-\ell_{t-1}\right)+(1-\beta *) \mathrm{b}_{t-1}
\end{aligned}
$$

where $\ell_{t}$ is an estimate of the level of the series at time $t, b_{t}$ is an estimate of the trend (slope) of the time series at time $t$ and $\alpha$ is the smoothing parameter for the level, $0 \leq \alpha \leq 1$, and $\beta^{*}$ is the smoothing parameter for the trend, $0 \leq \beta \leq 1$. The level equation here shows that $\ell_{t}$ is a weighted average of observation $y_{t}$ and the one-step-ahead training forecast for time $t$, given by $\ell_{t-1+b_{t-1}}$. The trend equation shows that $b_{t}$ is weighted average of the estimated trend at time $t$ based on $\ell_{t}-\ell_{t-1}$ and $b_{t-1}$, the previous estimate of the trend. The forecast function is no longer flat but trending. The h-step-ahead forecast is equal to the last estimated level plus $\mathrm{h}$ times the last estimated trend value. Hence the forecasts are a linear function of $\mathrm{h}$ (Hyndman and Anthanasopoulos, 2018).

ARIMA modeling is one of the most popular approaches to time series forecasting. While exponential smoothing models are based on a description of the trend and seasonality in the data, ARIMA model aims to describe the auto-correlations in the data. It explains a given time series based on its own past values, that is, its own lags and the lagged forecast errors, so that equation can be used to forecast future values. The ARIMA model is denoted by ARIMA $(p, d, q)$, where ' $p$ ' stands for the order of the auto regressive process, ' $d$ ' is the order of the data stationary and ' $\mathrm{q}$ ' is the order of the moving average process. The general form of the ARIMA (p,d,q) can be written as described by Judge, et al. (1988). 
$\Delta^{d} Z_{t}=\mathrm{C}+\left[\phi_{1} \Delta^{d} Z_{t-1}+\cdots+\phi_{p} \Delta^{d} Z_{t-p}-\left(\phi_{1} e_{t-1}+\cdots+\phi_{p} e_{t-p}\right)+e_{t}\right.$

where, $\Delta^{\mathrm{d}}$ denotes differencing of order d, i.e., $\Delta \mathrm{Z}_{\mathrm{t}}=\mathrm{Z}_{\mathrm{t}}-\mathrm{Z}_{\mathrm{t}-1}, \Delta^{2} \mathrm{Z}_{\mathrm{t}-1}=\Delta \mathrm{Z}_{\mathrm{t}}-\Delta \mathrm{Z}_{\mathrm{t}-1}$ and so on, $\mathrm{Z}_{\mathrm{t}-1}$----- $\mathrm{Z}_{\mathrm{t}-\mathrm{p}}$ are past observations (lags), ' $\mathrm{C}$ ' is a constant and $\phi_{1--------} \phi \mathrm{p}$ are coefficient to be estimated by auto regressive model. The auto regressive model of order ' $p$ ' denoted by AR $(\mathrm{P})$ and is written as

$$
Z_{t}=\mathrm{C}+\phi_{1} Z_{t-1}+\phi_{2} Z_{t-2}+\cdots+\phi_{p} Z_{t-p}+e_{t}
$$

where, $e_{t}$ is a random variable with zero mean and constant variance. In the moving average (MA) model, coefficient ' $F$ ' needs to be estimated. So MA model of order q can be written as:

$$
Z_{t}=e_{t}-\phi_{1} \mathrm{e}_{t-1}-\phi_{2} \mathrm{e}_{t-2}-\cdots-\phi_{q} \mathrm{e}_{t-q}
$$

The degree of the homogeneity (d) was determined on the basis of auto correlation function (ACF) until ACF moves toward zero. Then after calculating'd' one need to examine a stationary series $\Delta^{\mathrm{d}} \mathrm{Z}_{\mathrm{t}}$, along with its auto correlation function and partial autocorrelation to determine the values of $\mathrm{p}$ and $\mathrm{q}$. Since a large number of factors affects the water level and water quality and usually shows non linear relation with the variables; so traditional data processing methods are not good enough (Xiang et al. 2006). Therefore, ANN approach has advantages over semi-empirical models, since they require known input data set without any assumptions and develops a mapping of the input and output variables, which can subsequently be used to predict desired output as a function of suitable inputs (Schalkoff, 1992; Gardner and Dorling, 1998). Multilayer Perceptron Neural Network (MLPNN) can approximate any smooth, measurable function between input and output vectors by selecting a suitable set of connecting weights and transfer functions (Singh et al. 2009). The ANN model has three or more layers: the input layer where the data are introduced to the model and computation of the weighted sum of the input is performed, the hidden layer or layers where data are processed, and the output layer, where the results of ANN are produced. Each layer consists of one or more basic element called a neuron or a node. The signal passing through the node is modified 
by weights and transfer functions. Each node in the input and inner layers receives input values, process it, and passes it to the next layer. This process is repeated until the output layer is reached (Govindaraju 2000). The number of neurons in the input, hidden and output layers depends on the problem, if number of hidden neurons is small, the network may not have sufficient degrees of freedom to learn the process correctly however, if the number is too high, the training will take longer time and the network may over-fit the data (Karunanithi et al. 1994).

For development of an optimized neural model, a wide range of models are developed, trained and used for prediction of water quality parameters for the year 2019 based on data of previous years. Predicted values of water quality parameters for year 2019 is then compared with the observed values of 2019 using $\mathrm{r}^{2}$ and RMSE criterion discussed in next section. Based on the performance evaluation criteria the optimized neural network with best performance is then used for comparing it with other time series forecasting methods. In this study three learning algorithms viz. networks using backpropagation, resilient backpropagation (RPROP) with (Riedmiller 1994) or without weight backtracking or the modified globally convergent version (GRPROP) by Anastasiadis et al. (2005) were used for testing and selection of best fit ANN model towards predicting groundwater level in Phagi tehsil at village level.

Implementation of these algorithms in neuralnet $r$ language package were utilized to develop different models of neural networks. Fig. 5 shows the typical neural architecture with

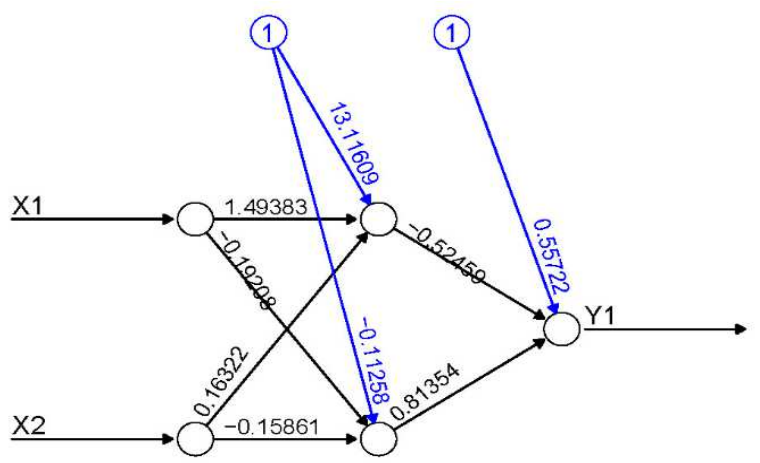

Fig. 5 Typical neuralnet diagram showing relationship between inputs, neurons and output 
inputs, outputs and neurons in hidden layer. A large number of ANN Models were developed using variations in input data such as models which used village area as an input variable or not, water table rise as an input or not and annual rainfall as input or not besides other inputs such as previous years values of water quality parameters. After the finalization of input matrix, the data was normalized in the range from $[0,1]$. Various models were also developed to try different combinations of hidden layers and number of neurons in different hidden layers, for examples single hidden layer with 3, 4 and 5 and two hidden layers with combinations such as $(3,1)(4,1),(4,2),(5,1),(5,2)$ and $(5,3)$ were used.

Using trial and error and evaluating with values of $r^{2}$ and RMSE, it was found that resilient backpropagation with weight backtracking (algorithm $=$ "rprop+"in $r$ language implementation), using water level as input besides previous years values of water quality parameters and with hidden layers having 4 and 2 neurons respectively provided the optimum neural architecture for prediction of future water quality parameters at village level. A threshold value of 0.01 was used for the partial derivatives of the error function as stopping criteria. A maximum number of steps of $1 \times 10^{5}$ was used as stopping criteria for the neural network's training process. Multiplication factors of 0.5 and 1.2 were used for the upper and lower learning rate. Sum of squared errors differentiable function was used for the calculation of the error.

To determine optimum percentage of data between training and validation, models with $55 \%$ to $85 \%$ randomly chosen data were used and k-fold cross-validation method was used to validate the model. For each percentage of training sample varying from $55 \%$ to $85 \%$ in increment of $1 \%$, total dataset was partitioned into 100 randomly allotted training and testing samples and ANN model was developed for each such set. This ensures that every data point gets a chance to be in test set and training set, thus this method reduces the dependence of 


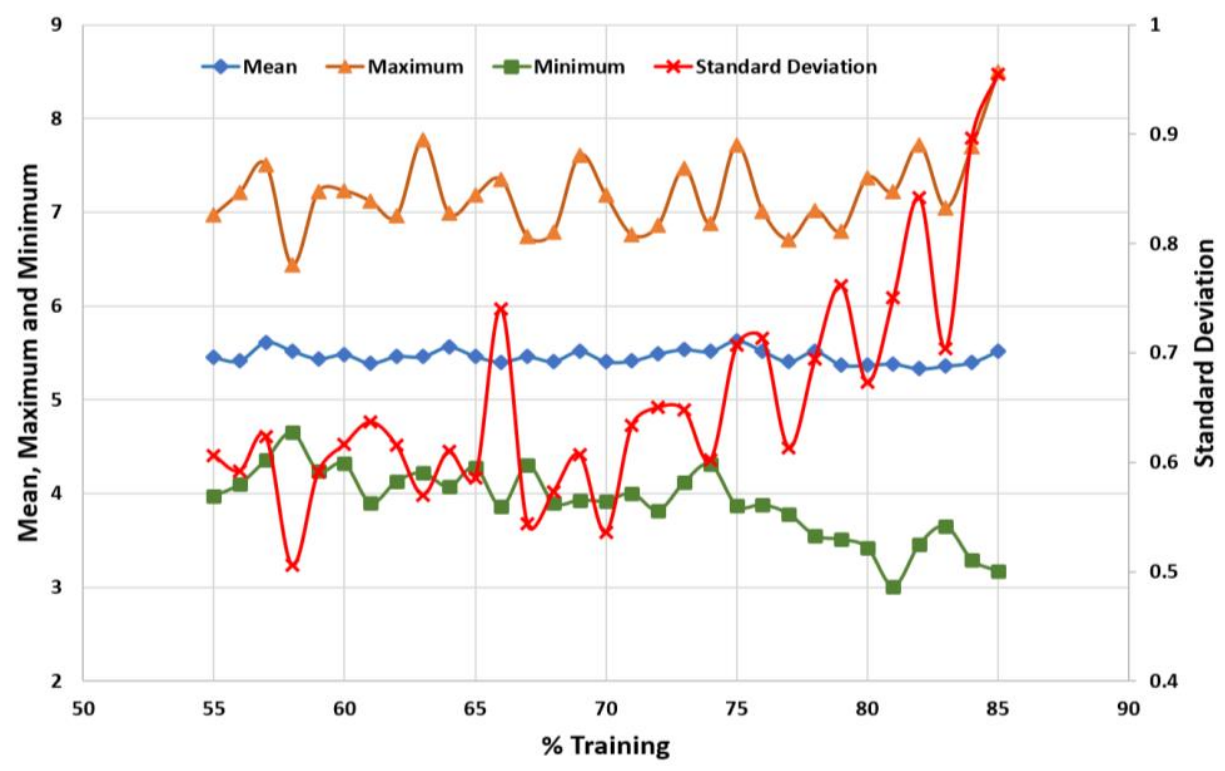

Fig. 6 Optimum \% training using $\mathrm{k}$ fold cross-validation method

performance on test-training split and reduces the variance of performance metrics. Mean, maximum, minimum and standard deviation of $\mathrm{r}^{2}$ for all 100 models were determined for each $\%$ or training set and plotted as shown in Fig. 6. It can be seen that beyond $70 \%$, standard deviation is continuously rising indicating over training. Therefore $70 \%$ was used as optimum training percentage.

\subsubsection{Model Performance evaluation}

The performance of the applied models can be assessed by several statistical error measures. The root mean square error (RMSE), mean absolute error (MAE) and Nash-Sutcliffe coefficient of efficiency (NSE) were used to provide an indication of goodness of fit between the observed and predicted values. Expressions of these error parameters are given as follows:

$$
R M S E=\sqrt{\frac{1}{N} \sum\left(X_{\text {Observed }}-X_{\text {predicted }}\right)^{2}}
$$




$$
\begin{aligned}
& M A E=\frac{1}{N} \sum\left|X_{\text {predicted }}-X_{\text {observed }}\right| \\
& N S E=1-\left[\frac{\sum\left(X_{\text {observed }}-X_{\text {predicted }}\right)^{2}}{\sum\left(X_{\text {observed }}-X_{\text {mean observed }}\right)^{2}}\right]
\end{aligned}
$$

where $N=$ total number of observations in the data set. NSE determines the relative magnitude of the residual variance ("noise") compared to the measured data variance ("information") (Nash and Sutcliffe 1970). NSE indicates how well the plot of observed versus simulated data fits the 1:1 line and ranges from negative infinity to 1 . The model is deemed perfect when NSE is greater than 0.75 , satisfactory when NSE is between 0.36 and 0.75 , and unsatisfactory when NSE is smaller than 0.36 (Krause et al. 2005). Another important indicator is percent bias (PBias), which measures the average tendency of the simulated values to be larger or smaller than their observed ones. The optimal value of PBias is 0.0 , with low-magnitude values indicating accurate model simulation. Positive values indicate over-estimation bias, whereas negative values indicate model under-estimation bias.

In order to evaluate optimum model out of multiple models an important criteria used is Akaike information criteria (AIC). AIC estimates the sample prediction error and therefore evaluates relative quality of different models for same set of data. Thus, AIC value could be used for selection of optimum model out of multiple models. AIC is defined as (Poeter and Hill, 2007; Zhou and Herath, 2017)

$$
\begin{aligned}
& A I C=n \ln \left(\sigma^{2}\right)+2 k \\
& \sigma^{2}=\frac{1}{n} \sum_{i=1}^{n} \omega_{i}\left[y_{i}-y_{i}^{\prime}\right]^{2}
\end{aligned}
$$

Where $\mathrm{n}$ is the number of observations, $\mathrm{k}$ is the number of model parameters, $\omega_{\mathrm{I}}$ is the weight for the $\mathrm{i}^{\text {th }}$ observation and $y_{i}, y_{i}^{\prime}$ are measured and model calculated observation parameter, respectively. AIC values were used to find optimum ANN models out of multiple ANN models developed based on variations in input, structure and algorithm of ANN models. 
2.3.5 Water Quality Index (WQI) estimation

Water Quality Index (WQI) is a very useful and efficient method for assessing the overall quality of water and to evaluate the suitability of the groundwater for drinking purposes (Abassi 1999; Asadi et al. 2007). For computing WQI, each of the four parameters has been assigned a weight $\left(w_{i}\right)$ according to its relative importance in the overall quality of water for drinking purposes (Ramakrishnaiah et al. 2009) and the relative weight $\left(W_{i}\right)$ is computed from the following equation:

$$
W_{i}=\frac{w_{i}}{\sum_{i=1}^{n} w_{i}}
$$

where, $W_{i}=$ relative weight, $w_{i}=$ weight of each parameter, and $n=$ number of parameters. Then quality rating scale $\left(q_{i}\right)$ is calculated for each parameter using following equation:

$$
q_{i}=\left(\frac{C_{i}}{s_{i}}\right) * 100
$$

where $q_{i}=$ quality rating for $i^{t h}$ parameter, $C_{i}=$ concentration of each chemical parameter in each water sample in $\mathrm{mg} / \mathrm{l}$, and $S_{i}=$ drinking water standard for each chemical parameter in mg/l according to the guidelines of World Health Organisation (WHO 2017). SI is first determined for each chemical parameter, which is then used to determine the WQI as per the following equation

$$
\begin{aligned}
& S I_{i}=W_{i} * q_{i} \\
& W Q I=\sum S I_{i}
\end{aligned}
$$

$S I_{i}=\operatorname{sub}$ index of $i^{\text {th }}$ parameter; $q_{i}=$ rating based on concentration of $i^{\text {th }}$ parameter, and $n=$ number of parameters. The computed WQI values are classified into five types, i.e. excellent (WQI <50), good (WQI = 50-100), poor (WQI = 100-200), very poor (WQI = 200-300), and water unsuitable for drinking (WQI >300).

Table 3 Groundwater Quality parameters, their WHO standards and assigned unit weights 


\section{Results and discussions}

3.1 Groundwater level prediction using time series forecasting models and ANN

In present study different time series forecasting models (SES, HTM, ARIMA) and ANN models were used used to predict water table level and important water quality parameters accurately with a relatively small error at village level for the year 2019 . Usually in the time series research studies, appropriate models for forecasting are selected on the basis of minimum values of RMSE, MAE, Akaike Information criterion (AIC), with high $\mathrm{R}^{2}$ and NSE. Hence, in this research performance of models was evaluated by comparing the simulated and observed outcomes of SES, HTM and ARIMA with optimum ANN model for the year 2019 and then best method was selected to predict the values for the year 2024. Table 4 and Fig. 7 clearly indicate that ARIMA is capable of producing better results $\left(\mathrm{R}^{2}=0.97, \mathrm{MAE}=1.83, \mathrm{NSE}=\right.$ 0.71, Pbias = 3.6) in comparison of HTM and SES. It was also found that ANN15 achieved

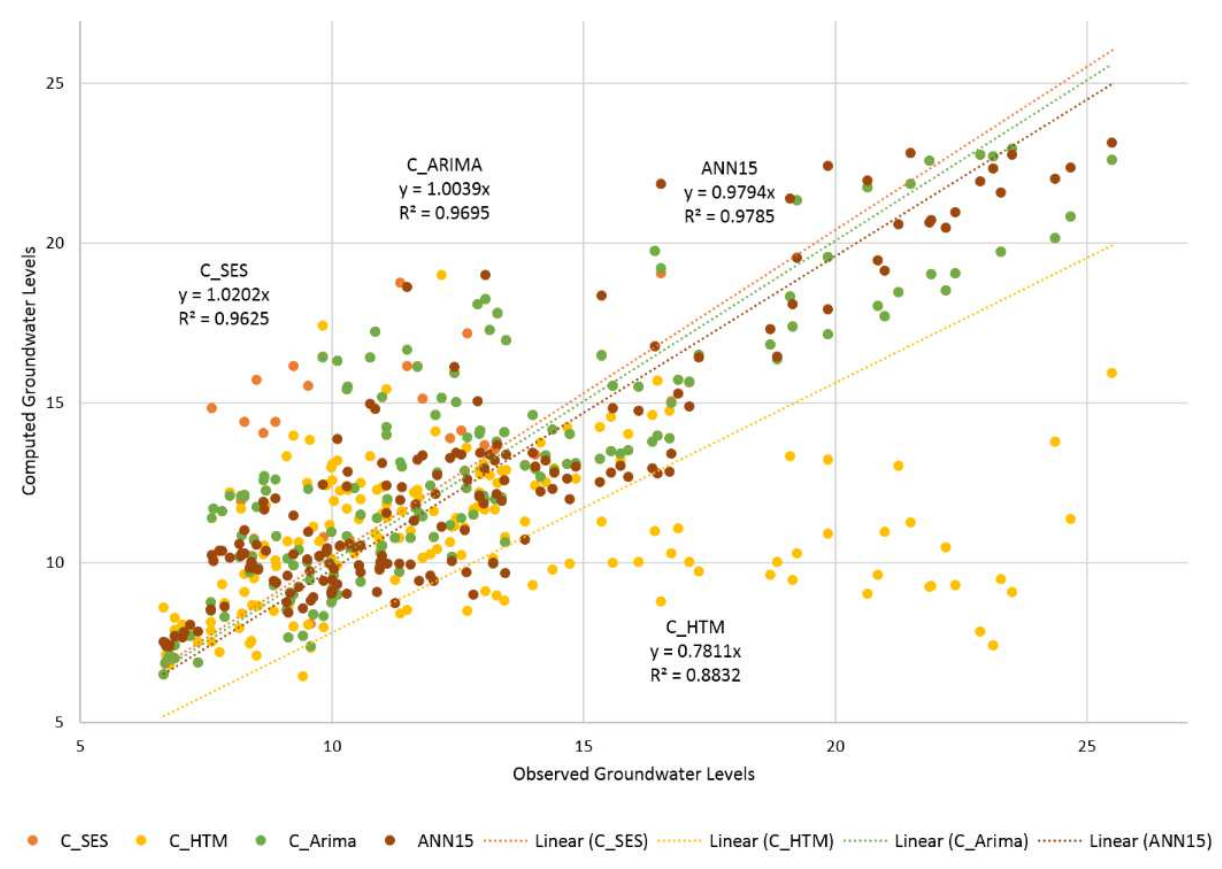

Fig. 7 Performance of Time series forecasting models and ANN an acceptable range of error distribution for groundwater level prediction with $\mathrm{R}^{2}=0.98$, and $\mathrm{NSE}=0.81$. The values of RMSE, PBias and AIC are minimum for ANN model followed by 
ARIMA model. So this specifies that ANN model gives the best estimation of future values and is used in further analysis.

Table 4 Comparison of Time series forecasting models with ANN

\subsection{Groundwater level prediction using ANN models}

Results (Fig. 8) infer that spatial distribution of observed and simulated groundwater level values obtained from ANN15 is capable of close-fitting the hidden relationships in the time series datasets. Therefore, ANN15 was used to forecast the groundwater level in the study area. It is evident from spatial distribution (Fig. 8) that depth to water level varied upto $11 \mathrm{mbgl}$ in

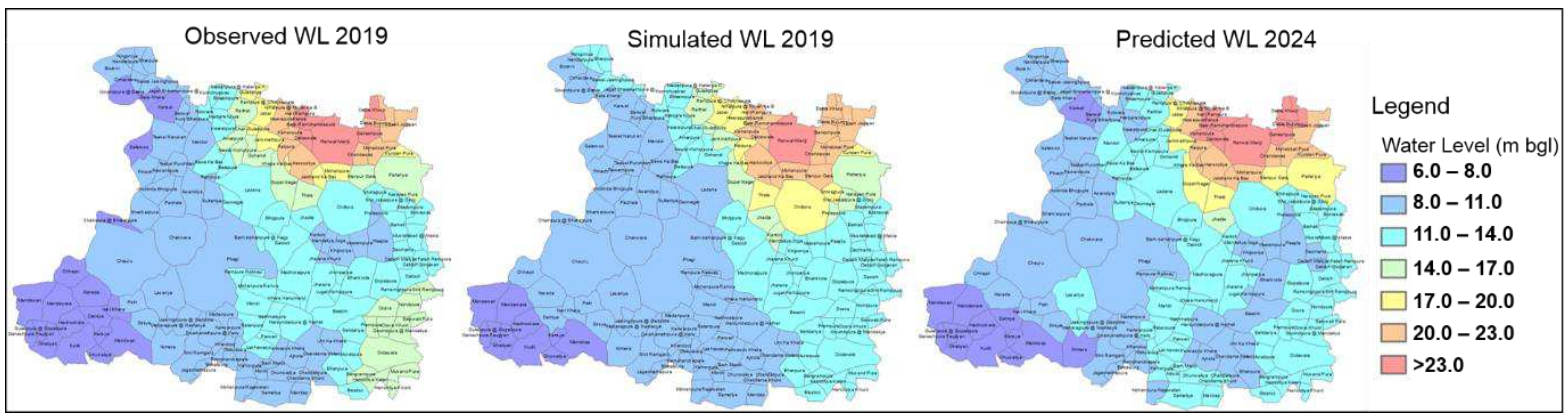

Fig. 8 Observed, simulated and predicted mean values of depth to water level (mbgl) for 2019 and 2024 (pre-monsoon period)

south-western part of Phagi tehsil, however situation is alarming in northern villages of Phagi tehsil as deeper water level were observed in Renwal Manjii (25.5mbgl), Beer Ramchandrapura (24.67mbgl), Daloowala (24.37mbgl), Ganeshpura (23.52mbgl), Hari Rampura (23.29mbgl) and Dabla Khurd (23.14mbgl) during pre-monsoon period of 2019. The water level predictions for year 2024 indicate that in next five years some more villages will face significant drop in groundwater level like Dabla Bujurg (23.6mbgl), Nihalpura@Miyan ka bas (23.16mbgl) and Karwa $(23.37 \mathrm{mbgl})$. 


\subsection{Water Level Scenario (2012- 2024)}

In present study, water table rise was evaluated during 2012 to 2024 by comparing two years data simultaneously. The spatial and temporal changes in water level rise/fall (Fig. 9) during pre-monsoon season of 2012-2013 indicates that most of the villages of Phagi tehsil shows more than $4 \mathrm{~m}$ rise especially in northen and central part of tehsil. However fall of $<2 \mathrm{~m}$ has been observed in 15 villages like Mendwas (-1.1m), Dhuwaliya (-1.09m), Nimera $(-1.24 \mathrm{~m})$ and Jagannathpura (-0.79m). The water level results of year 2018-2019 indicate drastic change in

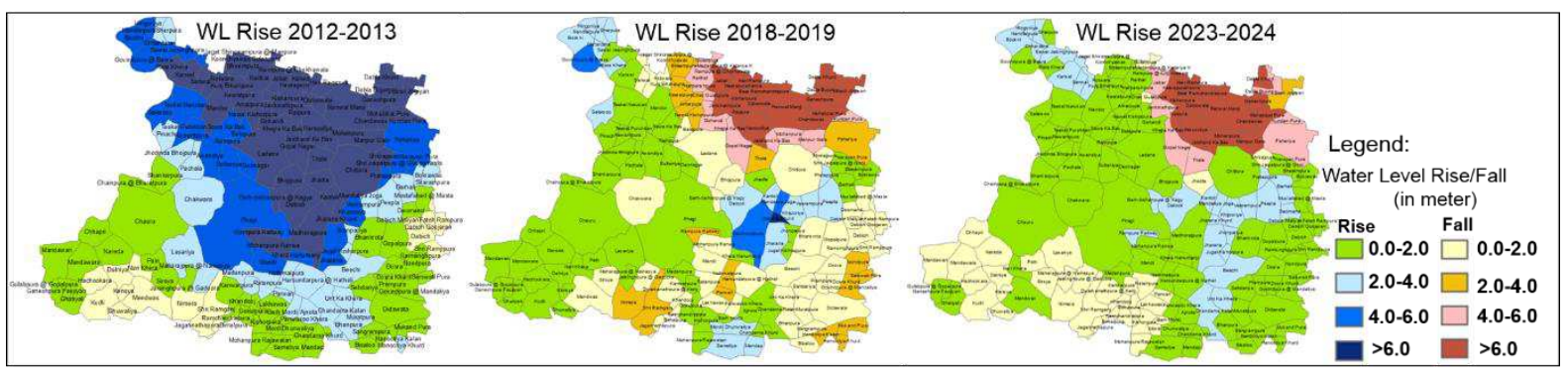

Fig. 9 Observed and predicted mean values of water table rise/fall in Phagi tehsil

groundwater recharge as only 4 villages showed $>4 \mathrm{~m}$ rise i.e. Mandaliya Joga $(4.21 \mathrm{~m})$, Madhorajpura (5.76m), Jharana Khurd (7.04m) and Govindpura@ Basra (4.15m). The decrease in groundwater of more than $6.0 \mathrm{~m}$ has been observed in northern villages of Phagi tehsil during 2018-2019, which indicates the excess utilization of groundwater for irrigation and domestic purposes. The ANN predicted results of 2023-2024 also infer the decrease of $>6.0 \mathrm{~m}$ in 16 villages like Heerapura (-9.08m), Nihalpura@Miyan ka bas (-10.06m), Hari Rampura (10.53m), Karwa (-10.21m), Renwal Manjii (-9.03m), Beer Ramchandrapura (-10.4m), Daloowala (-9.4m), and Chandawas (-9.69m). It is clearly evident that till 2024 the groundwater level will drop more and more quickly as not a single village shows $>4 \mathrm{~m}$ rise in Phagi tehsil. 
The spatial distribution (Fig.10a) of TDS varied from 1584.27 to $3077.36 \mathrm{mg} / \mathrm{l}$ during premonsoon season in 2019. The TDS values in entire Phagi tehsil exceeded the upper limit value of $1000 \mathrm{mg} / \mathrm{l}$ recommended by the WHO (2017) for drinking purposes. The groundwater with 500-1000 mg/l TDS is permissible for drinking, TDS <3000 mg/l useful for irrigation; however $>3000 \mathrm{mg} / \mathrm{l} \mathrm{TDS}$ is unfit for drinking and irrigation both (Davis and De Wiest 1966). Results

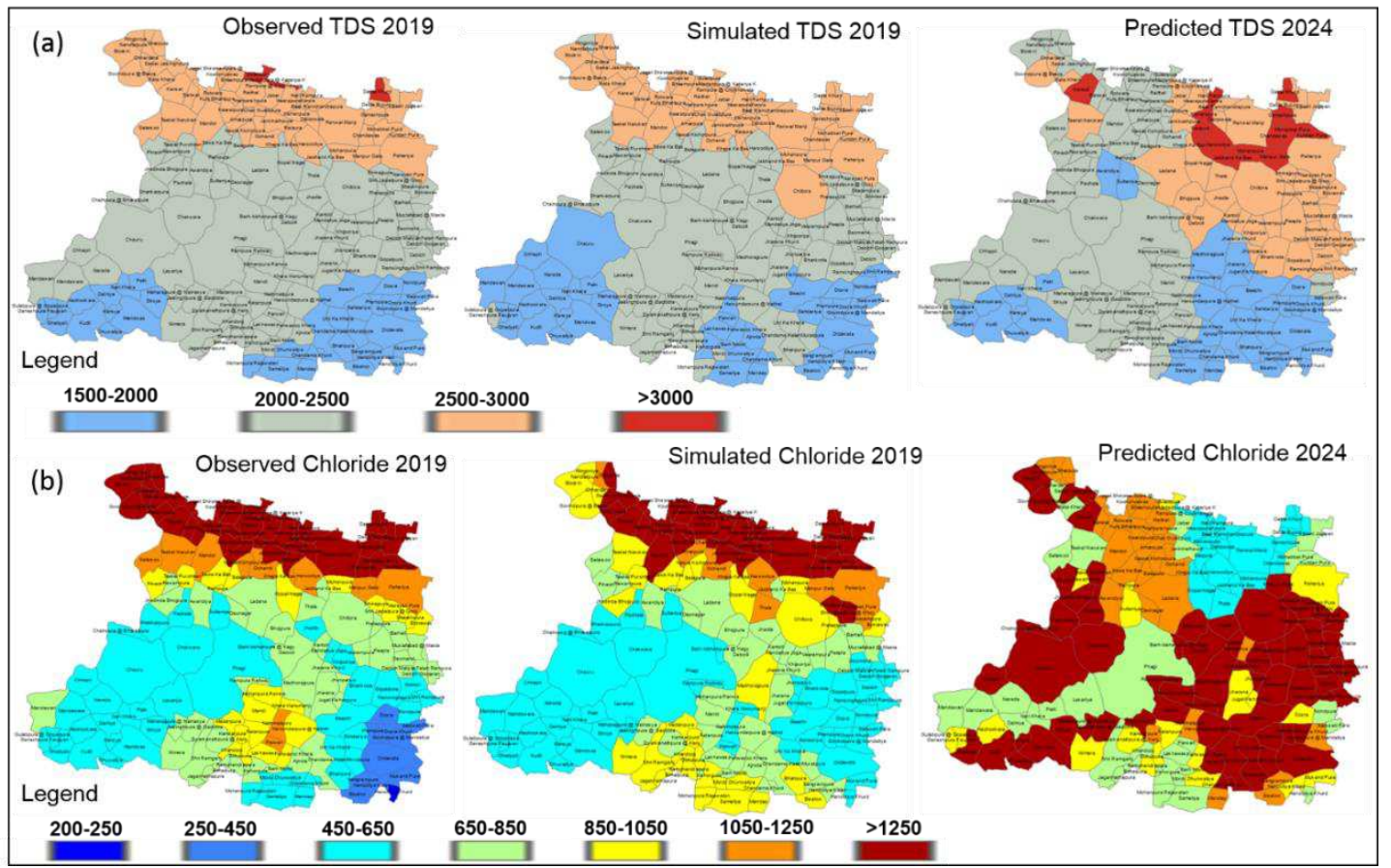

Fig. 10ab Observed, simulated and predicted mean values of TDS and chloride (in $\mathrm{mg} / \mathrm{l}$ ) for 2019 and 2024

implies very high TDS values (>2500 mg/l) in the northern villages of Phagi tehsil during 2019 and indicate that water is only suitable for irrigation purpose not for drinking, however five villages shows TDS concentration $>3000 \mathrm{mg} / \mathrm{l}$ like Dabla Khurd (3051.48mg/l), Madanpura@katariya ka bas (3058.77mg/l), Rampur@chokhawala (3023.41mg/l), Gulabpura (3077.36mg/l), Nihalpura@ Miyan ka bas (3008.18mg/l). Very high TDS concentration in groundwater may be due to the increase in salts containing carbonates, bicarbonates and chlorides (Singh et al. 2012). Moreover, high TDS concentration in northern villages may be 
attributed to the percolation of domestic sewage into the groundwater. The ANN predicted values of TDS in pre-monsoon period of 2024 indicate that 14 villages of Phagi tehsil will come under unfit groundwater category with very high concentration of TDS (>3000mg/l) in villages like Ganeshpura (3218.62mg/l), Mohabbatpura (3261.72mg/l), Harsooliya (3305.68mg/l), Mohanpura (3502.2mg/l), Jaichand ka bas (3277.06mg/l) and Manpur gate (3228.43mg/l). High TDS is responsible for decrease in palatability and gastro-intestinal irritation in humans (Sharma et al. 2017).

The chloride concentration (Fig. 10b) was found to be highly variable in the study area ranging from 244.42 to $1922.31 \mathrm{mg} / \mathrm{l}$ in 2019 . The permissible limit of chloride is $250 \mathrm{mg} / \mathrm{l}$ (WHO 2017) which is observed in only one village i.e. Hanootiya Khurd (244.42mg/l). The increase in chloride concentration is observed as index of pollution and indicates groundwater contamination (Sarath Prasanth et al. 2012). Very high concentration of Chloride (>1250mg/l) was observed in northern villages of the study area, this refers extreme groundwater contamination in northern part of Phagi tehsil. The villages which exceeded the chloride concentration (>1800mg/l) are Dabla Khurd (1893.42mg/l), Dabla Bujurg (1846.46mg/l), Rampur@chokhawala (1846.79mg/l), Madanpura@katariya ka bas $(1894.27 \mathrm{mg} / \mathrm{l})$, Bheempura (1804.31mg/l), Koonchyawas (1810.03mg/l) and Gulabpura (1922.31mg/l). The spatial distribution of ANNsimulated chloride values indicates almost same trend in 2019, however in 2024, ANNpredicted values shows different situation of chloride concetration in Phagi tehsil. Result implies that chloride concentration will range between $446.37 \mathrm{mg} / \mathrm{l}$ and $1816.95 \mathrm{mg} / \mathrm{l}$ in 2024 and refers that chloride concentration will be relatively lower in northern villages of tehsil in comparison to eastern and western villages. The higher concentration of chloride may affect the taste, indigestion and palatability in human (Bhunia et al. 2018).

The results of fluoride concentration (Fig.10c) reveal that fluoride ranged from 2.09 to 3.15mg/l in Phagi tehsil in 2019. The permissible limit for fluoride content is $1-1.5 \mathrm{mg} / \mathrm{l}$ (WHO 
2017) and spatial distribution results indicate that entire Phagi tehsil is affected with high concentration of fluoride. The main source of fluoride in groundwater is attributed to leaching from fluoride rich rocks, semi-arid climate, long-term irrigation processes and long residence

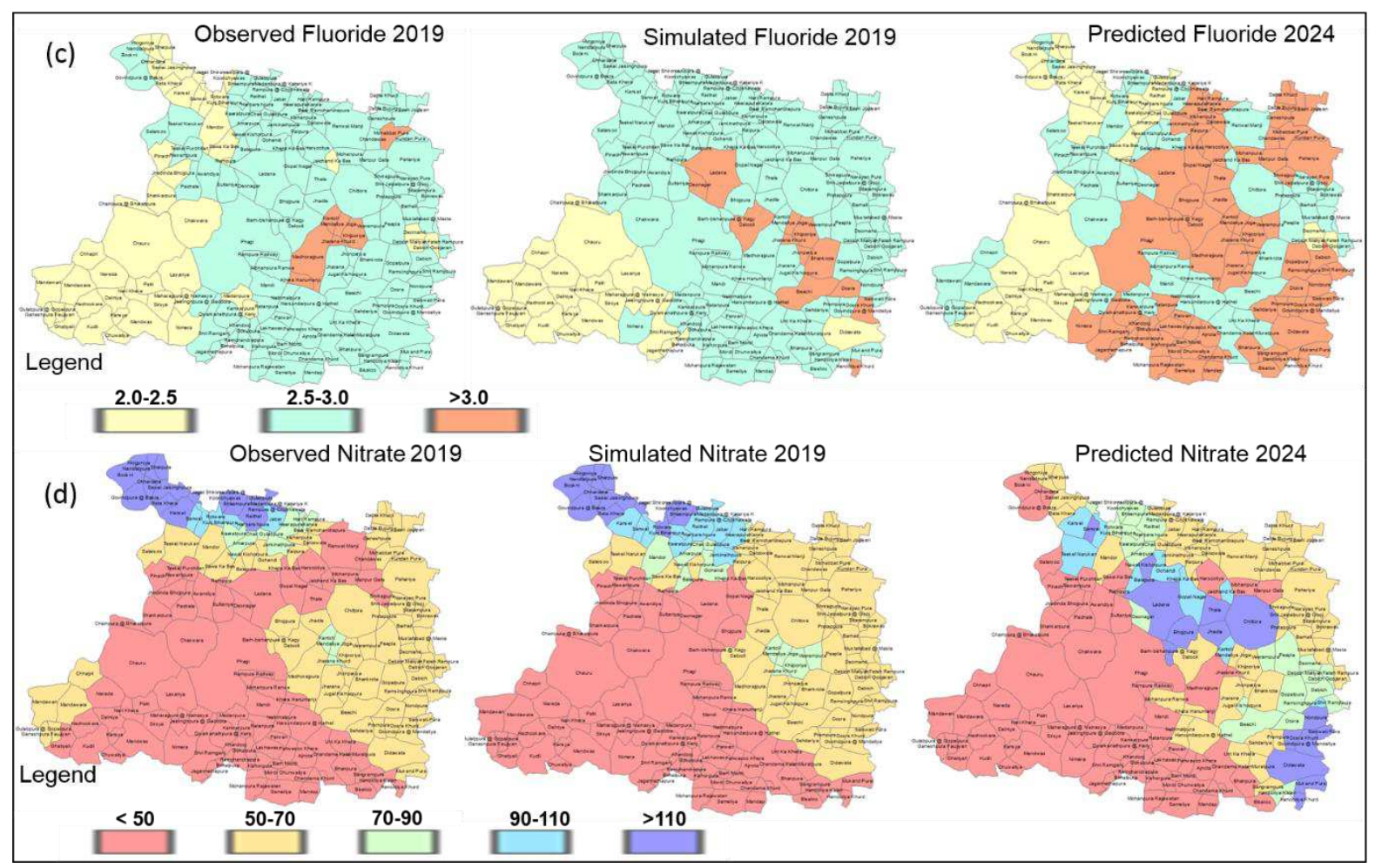

Fig. 10cd Observed, simulated and predicted mean values of Fluoride and Nitrate (in mg/l)

for 2019 and 2024

time of groundwater (Srinivasamoorthy et al., 2008). High fluoride $>1.2 \mathrm{mg} / \mathrm{l}$ results in dental fluorosis however fluoride $>2 \mathrm{mg} / \mathrm{l}$ initiate mottling (Singh et al. 2012). The observed data (2019) reveal that more than $3.0 \mathrm{mg} / \mathrm{l}$ fluoride has been found in Khera Hanumanji $(3.15 \mathrm{mg} / \mathrm{l})$, Jharana Khurd (3.05mg/l), Madhorajpura (3.04mg/l), Mandaliya Joga (3.07mg/l) and Mohabbatpura (3.02mg/l). However ANNsimulated data of 2019 reveal $>3.0 \mathrm{mg} / \mathrm{l}$ fluoride concentration in 12 villages of Phagi tehsil (Fig. 7c). The ANN predicted fluoride concentration for 2024 reveal that $47 \%$ of Phagi tehsil will be affected with $>3.0 \mathrm{mg} / \mathrm{l}$ fluoride especially in eastern, central and northern villages of the study area. The adverse effects due to consumption 
of fluoridated water are inevitably experienced by villagers in Phagi tehsil hence defluoridation of drinking water is requisite in the study area.

The groundwater data of Phagi tehsil shows that Madanpura@katariya ka bas village has maximum nitrate concentration $(135.81 \mathrm{mg} / \mathrm{l})$ while Barh Ramchandrapura had minimum (11.9 mg/l) in 2019. The observed and ANNsimulated results (Fig. 10d) for 2019 reveal that nitrate content is higher than the maximum permissible limit recommended by WHO (WHO 2017) in northern and eastern villages of Phagi tehsil. Excess of nitrate is dangerous for infants below six months age and when the concentration of nitrate ion exceeds $45-50 \mathrm{mg} / \mathrm{l}$, it causes methamoglobinemia in children (Sharma et. al. 2015). The higher content of nitrate (>120mg/l) will occur in Ladana $(135.59 \mathrm{mg} / \mathrm{l})$, Thala $(133.76 \mathrm{mg} / \mathrm{l})$, Chittora $(133.05 \mathrm{mg} / \mathrm{l})$, Bhojpura (135.77mg/l), Jhadla (135.43mg/l), Barh bishanpura@Kagya (134.44mg/l), Sarswatipura (134.42mg/l), Govindpura@ Mandaliya (135.22mg/l) and Mukandpura (134.72mg/l). The higher concentration of nitrate may be due to the sewage, organic matter and fertilizer from agricultural runoff (Annapoorna and Janardhana 2015).

\subsection{Water Quality Index}

The Water quality index (WQI) was developed to evaluate the suitability of groundwater for drinking purpose. The spatial and temporal changes (Fig. 11) during study period (2012 to 2024) indicates the degraded groundwater quality of Phagi tehsil. The WQI values for premonsoon season of the year 2012 reveal that only one village i.e. Deonagar showed excellent groundwater quality with the WQI 48.37, however very poor groundwater quality was observed in Chandawas (WQI 201.71), Mohabbatpura (WQI 200.68), Ganeshpura (WQI 224.46), Beer Ramchandrapura (WQI 211.51), Renwal Manji (WQI 218.67), Basri Jogiyan (WQI 214.15), Hari Rampura (WQI 200.69), Dabla Khurd (WQI 230.53) and Dabla Bujurg (WQI 225.69). 


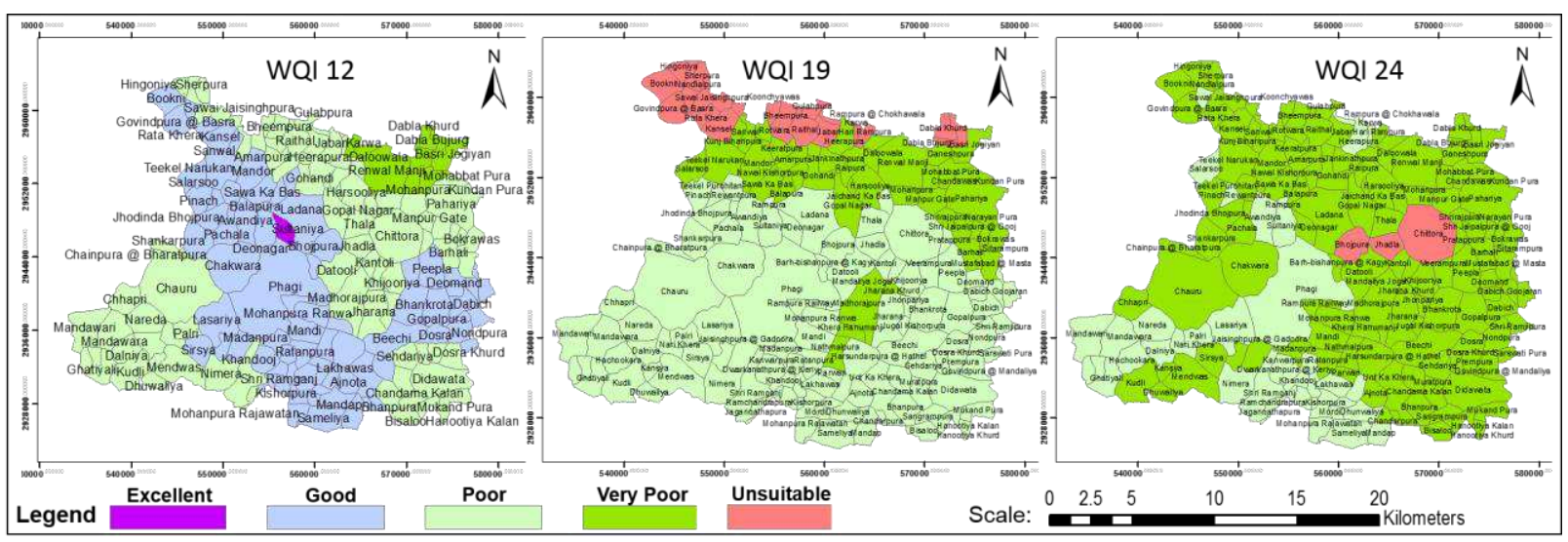

Fig. 11: Spatial variations in Water Quality Index (WQI) at village level during 20122024

The WQI for 2019 indicate that groundwater quality ranges in between 136.67-348.11. The WQI was found above 300 in 23 villages of northen part of Phagi tehsil and therefore groundwater cannot be used for drinking purpose. Five villages were with very high WQI (>330) like Madanpura@katariya ka bas (WQI 347.92), Bheempura (WQI 332.97), Koonchyawas (WQI 332.29), Gulabpura (WQI 348.10), and sherpura (WQI 330.09). The WQI for the year 2024 reveals that $74 \%$ villages of Phagi tehsil will have very poor groundwater quality with WQI ranging in between 200-300 and water cannot be used for domestic purposes. Predicted water quality values implies that three villages will come in WQI >300 category like Jhadla (WQI 337.31), Bhojpura (WQI 333.12) Chittora (WQI 336.89) and indicates that groundwater will be unfit for human consumption.

\section{Conclusions}

In general, the spatial and temporal results conclude that the Phagi tehsil is facing the problem of declining groundwater table along with deterioration in groundwater quality and posing a threat to public health. The groundwater risk villages were identified with the use of GIS and advanced modeling techniques for the pre-monsoon season. Different time series forecasting models and ANN models were compared to determine optimum model for prediction of the 
future scenarios of groundwater quality and quantity in 171 villages of Phagi tehsil. Results of the groundwater table shows the decline of $>6.0 \mathrm{~m}$ especially in northern villages of Phagi tehsil during the study period (2012-2024), which clearly indicates the excess utilization of groundwater for irrigation and domestic purposes. Hence, it is suggested that reduce the groundwater pumping and implement groundwater abstraction policy in high risk villages of the study area. Apart from this, the percolation tanks or farm ponds may be constructed to increase the natural recharge of rain water during monsoon period. Different groundwater quality parameters like TDS, chloride and fluoride indicated that groundwater is not suitable for drinking purpose in most of the villages of Phagi tehsil. The observed and ANNsimulated results for 2019 reveal high nitrate content in north-eastern villages however, ANNpredicted spatial distribution of nitrate for 2024 indicates that $58 \%$ villages of Phagi tehsil will exceed the maximum permissible limit for drinking. The WQI specifies very poor to unsuitable groundwater quality in $74 \%$ villages of the study area in 2024 indicating water cannot be used for domestic purposes. Thus, the spatio-temporal maps suggests the necessity of groundwater management with people's participation for more effective implementation of a mitigation strategy in Phagi tehsil at village level.

\section{Acknowledgment}

Authors acknowledge Department of Science \& Technology, Government of India for financial support vide reference number DST/WOS-B/2018/1575/ETD/Ankita under Women Scientist Scheme (WOS-B) to carry out this research work.

\section{Declarations}

Ethical Approval: Not applicable

Consent to Participate: This manuscript in part or in full has not been submitted or published anywhere. The manuscript will not be submitted elsewhere until the 
editorial/review process is completed.

Consent to Publish: Hereby all authors agree for publication of this manuscript in WARM Authors Contributions: All authors contributed to this manuscript

1. Dr. Ankita Pran Dadhich: Conceived and designed the analysis; performed analysis; wrote the manuscript

2. Dr. Rohit Goyal: Contributed in analysis tools and provided inputs in writing manuscript

3. Dr. Pran Nath Dadhich: Conceived \& Collected data and provided inputs in writing manuscript

Funding: Department of Science \& Technology, Government of India for financial support vide reference number DST/WOS-B/2018/1575/ETD/Ankita under Women Scientist Scheme (WOS-B) to carry out this research work.

Competing Interests: Not applicable

Availability of data and materials: Will be provided as per the requirement of Editor/ Reviewer

\section{References}

Abassi SA (1999) Water Quality Indices, State-of-the art. J.IPHE. No.1.

Ahmadi S, Sedghamiz A (2007) Geostatistical analysis of spatial and temporal variations of groundwater level. Environ Monit Assess 129(1-3):277-294

Anastasiadisa AD, Magoulasa GD, Vrahatis MN (2005) New globally convergent training scheme based on the resilient propagation algorithm. Neurocomputing 64:253-270 Annapoorna H, Janardhana MR (2015) Assessment of Groundwater Quality for Drinking Purpose in Rural Areas Surrounding a Defunct Copper Mine. Aquat Procedia 4:685 - 692 
Asadi SS, Vuppala P, Reddy MA (2007) Remote Sensing and GIS Techniques for Evaluation of Groundwater Quality in Municipal Corporation of Hyderabad (Zone-V), India. Int. J Environ Res Public Health 4(1): 45-52

Ay M, Kisi O (2012) Modeling of dissolved oxygen concentration using different neural network techniques in Foundation Creek, El Paso County, Colorado. J Environ Eng 138:654662

Bărbulescu A (2016) Studies on Time Series Applications in Environmental Sciences. Springer International Publishing, Cham, Switzerland. https://doi.org/10.1007/978-3-319-30436-6

Bhunia GS, Keshavarzi A, Shit PK, Omran ESE, Bagherzadeh A (2018) Evaluation of groundwater quality and its suitability for drinking and irrigation using GIS and geostatistics techniques in semiarid region of Neyshabur, Iran. Appl Water Sci 8:168

Brown, Robert G (1956). Exponential Smoothing for Predicting Demand. Cambridge, Massachusetts: Arthur D. Little Inc. p. 15.

Central Ground Water Board (2017) Report on aquifer mapping and ground water management, Jaipur District. Ministry of Water Resources, River Development \& Ganga Rejuvenation, Western Region Jaipur, Rajasthan Government of India.

Charulatha G, Srinivasalu S, Maheswari OU, Venugopal T, Giridharan L (2017). Evaluation of ground water quality contaminants using linear regression and artificial neural network models. Arab J Geosci 10:128

Chenini I, Ben MA (2010) Groundwater recharge study in arid region: an approach using GIS techniques and numerical modeling. Comput Geosci 36(6):801-817

Csábrági A, Molnár S, Tanos P, Kovács J (2017) Application of artificial neural networks to the forecasting of dissolved oxygen content in the Hungarian section of the river Danube. Ecol Eng 100:63-72 
Dadhich PN, Hanaoka S (2010) Remote sensing, GIS and Markov's method for land use change detection and prediction of Jaipur District. J Geomatics 4(1) 9-15

Davis SN, De Wiest RJM (1966). Hydrogeology, vol 463. Wiley, New York.

Gardner MW, Dorling SR (1998) Artificial neural networks (the multilayer perceptron)—a review of applications in the atmospheric sciences. Atm Environ 32(14-15):2627-2636

Gautam SK, Tziritis E, Singh SK, Tripathi JK, Singh AK (2018) Environmental monitoring of water resources with the use of PoS index: a case study from Subarnarekha River basin, India. Environ Earth Sci 77:70

Gharbia AS, Gharbia SS, Abushbak T, Wafi H, Aish A, Zelenakova M, Pilla F (2016) Groundwater Quality Evaluation Using GIS Based Geostatistical Algorithms. J Geosci Environ Prot 4(2):89-103

Ghazavi R, Vali AB, Eslamian S (2012) Impact of Flood Spreading on Groundwater Level Variation and Groundwater Quality in an Arid Environment. Water Resour Manage (2012) $26: 1651-1663$

Govindaraju RS (2000) Artificial neural network in hydrology. II: hydrologic application, ASCE task committee application of artificial neural networks in hydrology.J Hydrol Eng $5: 124-137$

Holt CC (1957) Forecasting Trends and Seasonals by Exponentially Weighted Averages, Carnegie Institute of Technology, Pittsburgh Office of Naval Research memorandum no. 52.

Hyndman RJ, Athanasopoulos G (2018) Forecasting: principles and practice. 2nd edition, OTexts: Melbourne, Australia. OTexts.com/fpp2.

Hyndman RJ, O'Hara-Wild M, Bergmeir C, Razbash S, Wang E (2017) Forecast: Forecasting functions for time series and linear models. $\mathrm{R}$ package version 8.2. https://CRAN.Rproject.org/package=forecast 
Jolly ID, McEwan KL, Holland KL (2008) A review of groundwater-surface water interactions in arid/semi-arid wetlands and the consequences of salinity for wetland ecology. Ecohydrology $1: 43-58$

Journel AG, (1989) In: Fundamentals of Geostatistics in Five Lessons, Short Course in Geology, vol. 8. American Geophysical Union.

Judge GG, Hill RC, William EG, Helmut I (1988) Introduction to the Theory and Practice of Econometrics. 2nd ed., John Wiley and Son, INC. New York, Toronto, Singapore

Karunanithi N, GrenneyWJ, Whitley D, Bovee K (1994) Neural networks for river flow prediction. ASCE J Comput Civil Eng 8:210-220.

Krause P, Boyle DP, Base F (2005) Comparison of different efficiency criteria for hydrological model assessment. Adv Geosci 5(1):89-97

Kumar VS, Amarender B, Dhakate R, Sankaran S, Kumar KR (2016) Assessment of groundwater quality for drinking and irrigation use in shallow hard rock aquifer of Pudunagaram, Palakkad District Kerala. Appl Water Sci 6:149-167

Marsily D, (1986). Quantitative Hydrogeology. Academic Press.

Measho S, Chen B, Trisurat Y, Pellikka P, Guo L, Arunyawat S, Tuankrua V, Ogbazghi W, Yemane T (2019) Spatio-Temporal Analysis of Vegetation Dynamics as a Response to Climate Variability and Drought Patterns in the Semiarid Region, Eritrea. Remote Sens 11:724

Minville M, Krau S, Brissette F, Leconte R (2010) Behaviour and performance of a water resource system in Québec (Canada) under adapted operating policies in a climate change context. Water Resour Manag 24:1333-1352

Mohanty, S., Jha, M. K., Kumar, A., \& Sudheer, K. P. (2010). Artificial neural network modeling for groundwater level forecasting in a river island of eastern India. Water Resour Manage 24:1845-1865 
Nas B, Berktay A (2010) Groundwater quality mapping in urban groundwater using GIS. Environ Monit Assess 160:215-227

Nash JE, Sutcliffe JV (1970) River flow forecasting through conceptual models. Part I-a discussion of principles. J Hydrology 10:282-290

Nayak TR, Gupta SK, Galkate R (2015) GIS Based Mapping of Groundwater Fluctuations in Bina Basin Aquat Procedia 4:1469 - 1476

Poeter EP, Hill MC (2007) MMA, a Computer Code for Multi-Model Analysis: U.S. Geological Survey Techniques and Methods 6eE3, Boulder, Colo, 113 p.

Ramakrishnaiah CR, Sadashivaiah C, Ranganna G (2009) Assessment of water quality index for the groundwater in Tumkar Taluk, Karnataka State, India. E-J Chem 6(2):523-530

Ratti C, Richens P (2004) Raster Analysis of Urban Form. Environ Plann B Plann Des 31(2): 297-309

Rawat KS, Singh SK, Gautam SK (2018) Assessment of groundwater quality for irrigation use: a peninsular case study. Appl Water Sci 8:233

Riedmiller M (1994) Rprop - Description and Implementation Details. Technical Report. University of Karlsruhe.

Sarath Prasanth SV, Magesh NS, Jitheshlal KV, Chandrasekar N, Gangadhar K (2012) Evaluation of groundwater quality and its suitability for drinking and agricultural use in the coastal stretch of Alappuzha District, Kerala, India. Appl Water Sci 2:165-175

Schalkoff R (1992) Pattern Recognition: Statistical, Structural and Neural Approaches, Wiley, New York, 364 p.

Sharma DA, Rishi MS, Keesari T (2017) Evaluation of groundwater quality and suitability for irrigation and drinking purposes in southwest Punjab, India using hydrochemical approach. Appl Water Sci 7:3137-3150 
Sharma SK, Sharma U, Chandel CPS (2015) Qualitative aspects of Ground water for Drinking purpose of Phagi Block of Jaipur District (Rajasthan). Ascent Int J Res Analysis 2(2): 57.157.9

Singh K, Basant A, Malik A, Jain G (2009) Artificial neural network modeling ofthe river water quality—a case study. Ecol Modell 220:888-895

Singh P, Fahmi N, Singh VP, Singh RV (2012) Studies on Ground Water Fluoride Content and Water quality in Phagi Tehsil of Jaipur District. Int J Chem Environ Pharm Res 3(3): 219-224 Singh SK, Srivastava PK, Pandey AC, Gautam SK (2013) Integrated assessment of groundwater influenced by a confluence river system: concurrence with remote sensing and geochemical modelling. Water Resour Manag 27(12):4291-4313

Srinivasamoorthy K, Chidambaram S, Vasanthavigar M (2008) Geochemistry of fluorides in groundwater, Salem District, Tamilnadu, India. J Env Hydrol 1:16-25

Srivastava PK, Gupta M, Mukherjee S (2012) Spatial distribution of pollutants in groundwater of a tropical area of India using remote sensing and GIS. Appl Geomatics 4:21-32

Sunayana, Kalawapudi K, Dube O, Sharma R (2019) Use of neural networks and spatial interpolation to predict groundwater quality.Environ Dev Sustain 22: 2801-2816

Ta'any RA, Tahboub AB, Saffarini GA (2009) Geostatistical analysis of spatiotemporal variability of groundwater level fluctuations in Amman-Zarqa basin, Jordan: a case study. Environ Geol 57:525-535

Verma DK, Bhunia GS, Shit PK, Kumar S, Mandal J, Padbhushan R (2017) Spatial variability of groundwater quality of Sabour block, Bhagalpur district (Bihar, India). Appl Water Sci $7: 1997-2008$

WHO. (2017). Guidelines for drinking water quality: training pack (4th ed.). Geneva, Switzerland: Incorporating The First Addendum 
Xiang SL, Liu ZM, Ma LP (2006) Study of multivariate linear regression analysis model for ground water quality prediction. Guizhou Sci 24(1):60-62

Yesilnacar MI, Sahinkaya E, Naz M, Ozkaya B (2008) Neural network prediction of nitrate in groundwater of Harran Plain, Turkey. Environ Geology 56(1):19-25

Zhou Y, Herath HMPSD (2017) Evaluation of alternative conceptual models for groundwater modelling, Geosci Front 8(3):437-443 

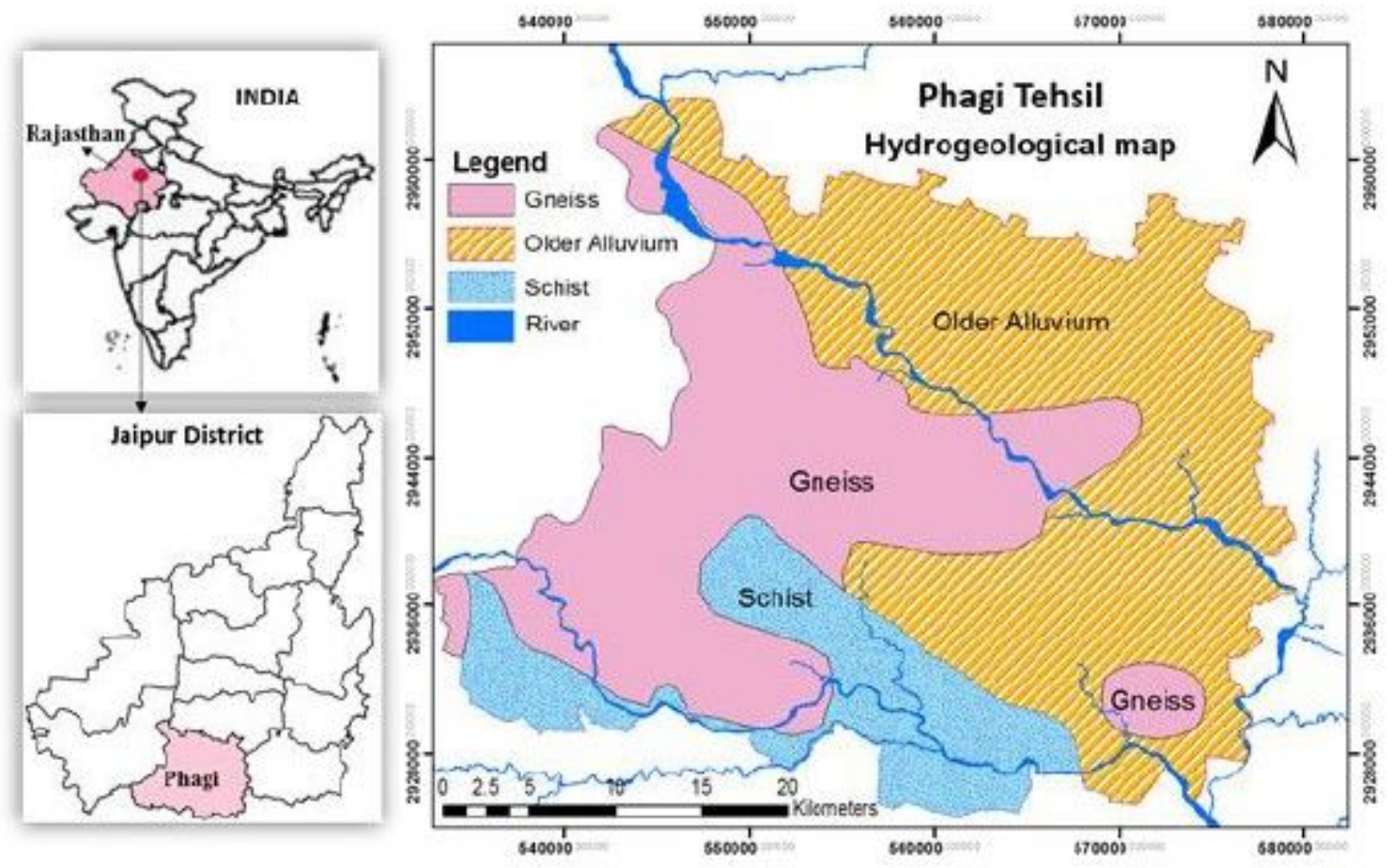

\section{Figure 1}

Location and Hydrogeology of the study area

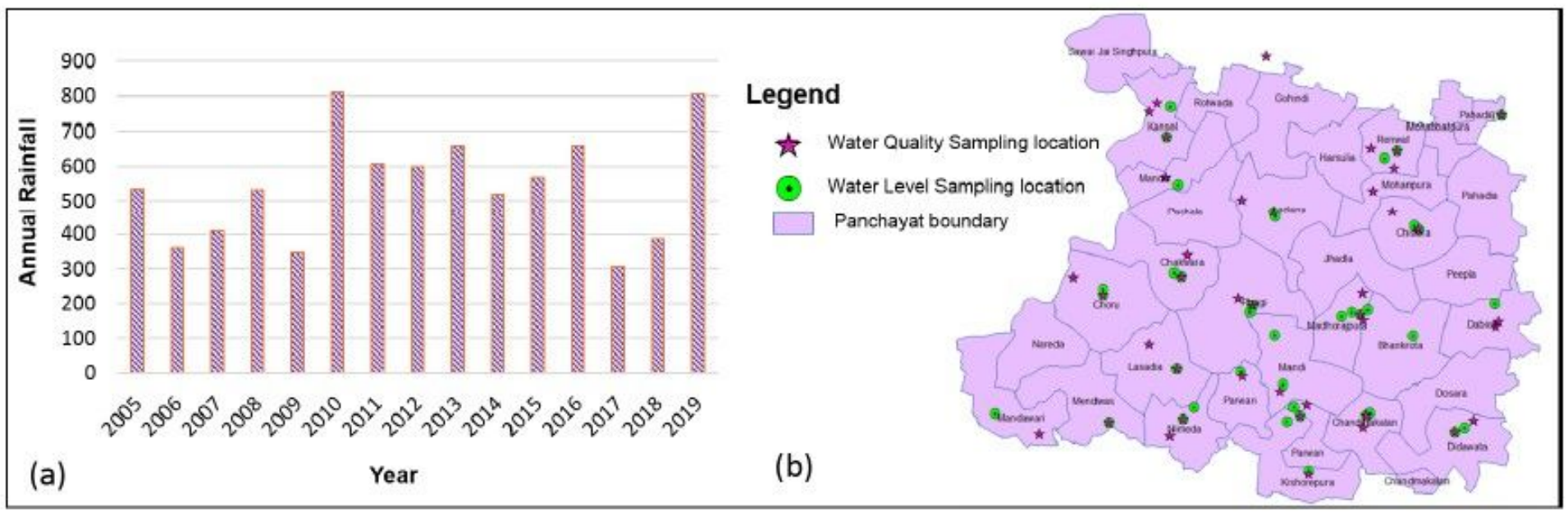

Figure 2

(a) Variations in annual rainfall (2005-2019) source: Central Ground Water Board, Jaipur (b) Sampling locations in Phagi Tehsil 


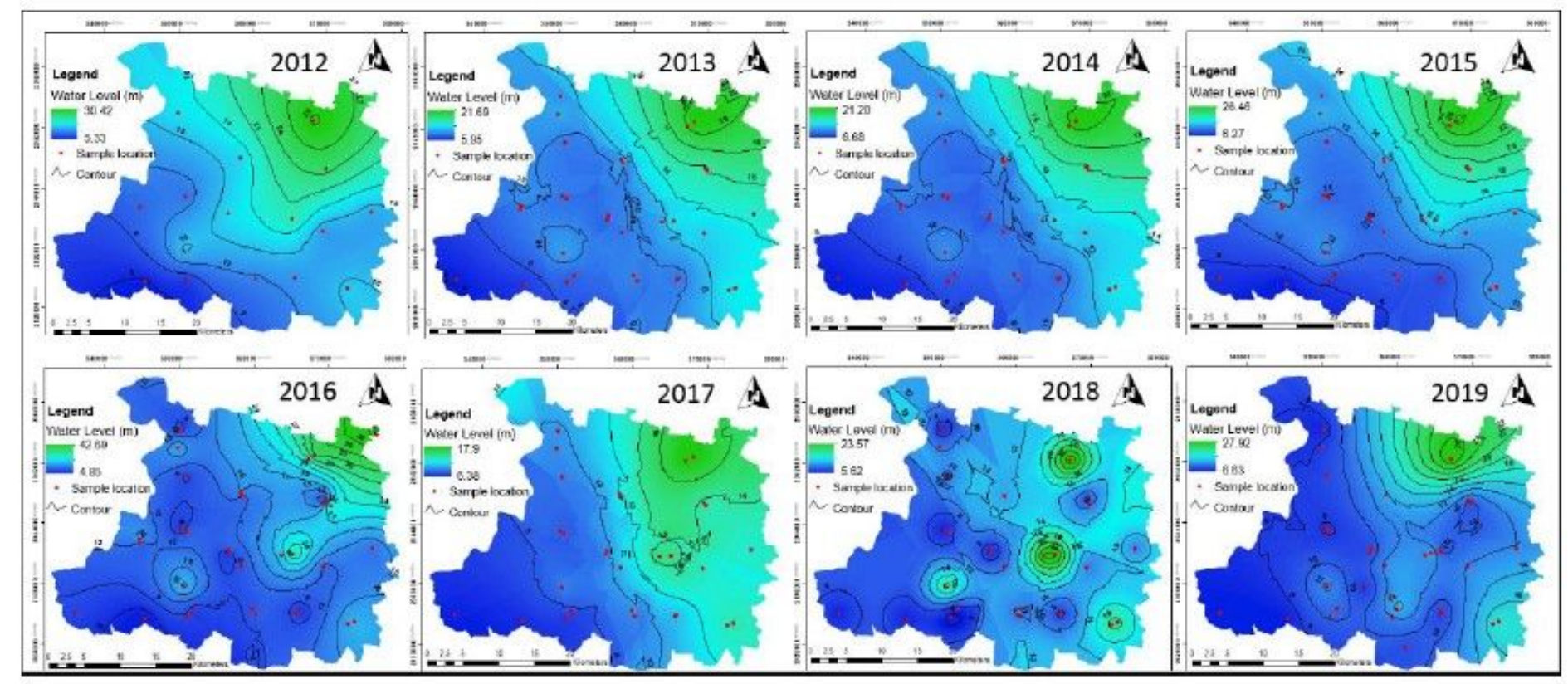

Figure 3

Spatial and temporal variability in groundwater level during 2012-2019 (pre-monsoon)

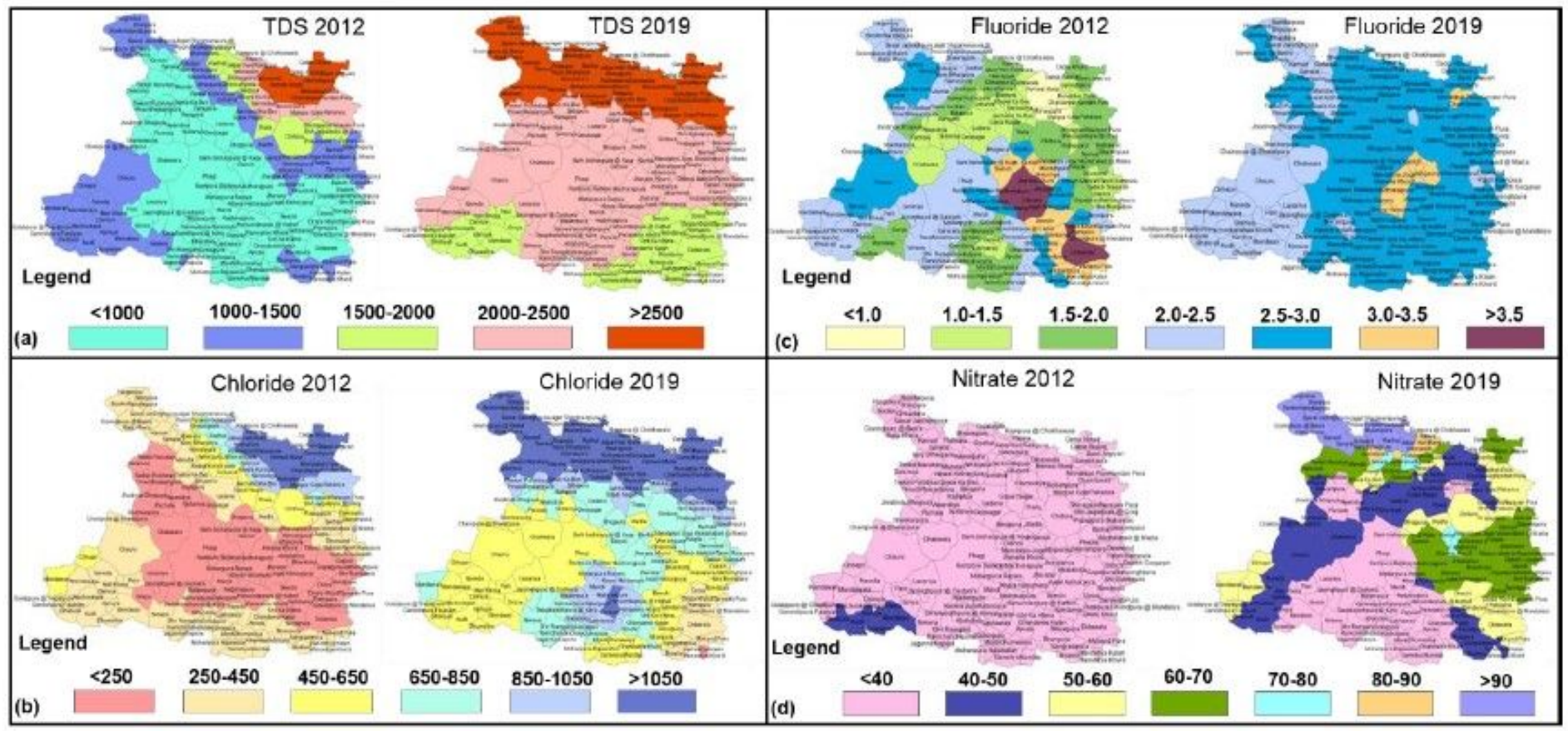

Figure 4

Temporal changes in groundwater quality (in $\mathrm{mg} / \mathrm{l}$ ) from 2012 to 2019 


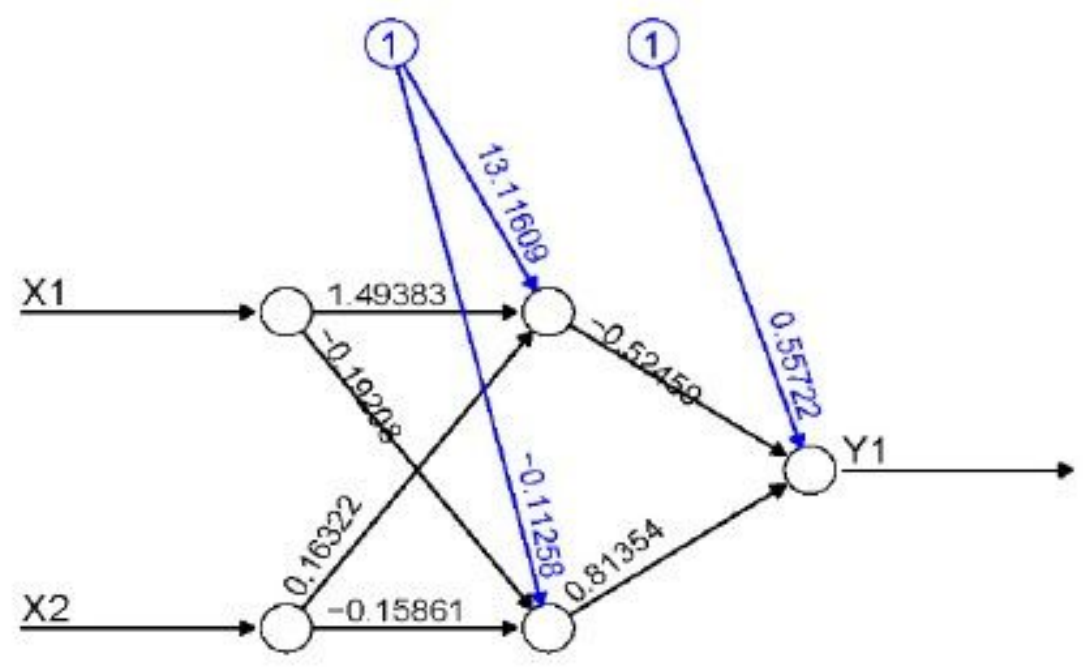

Figure 5

Typical neuralnet diagram showing relationship between inputs, neurons and output

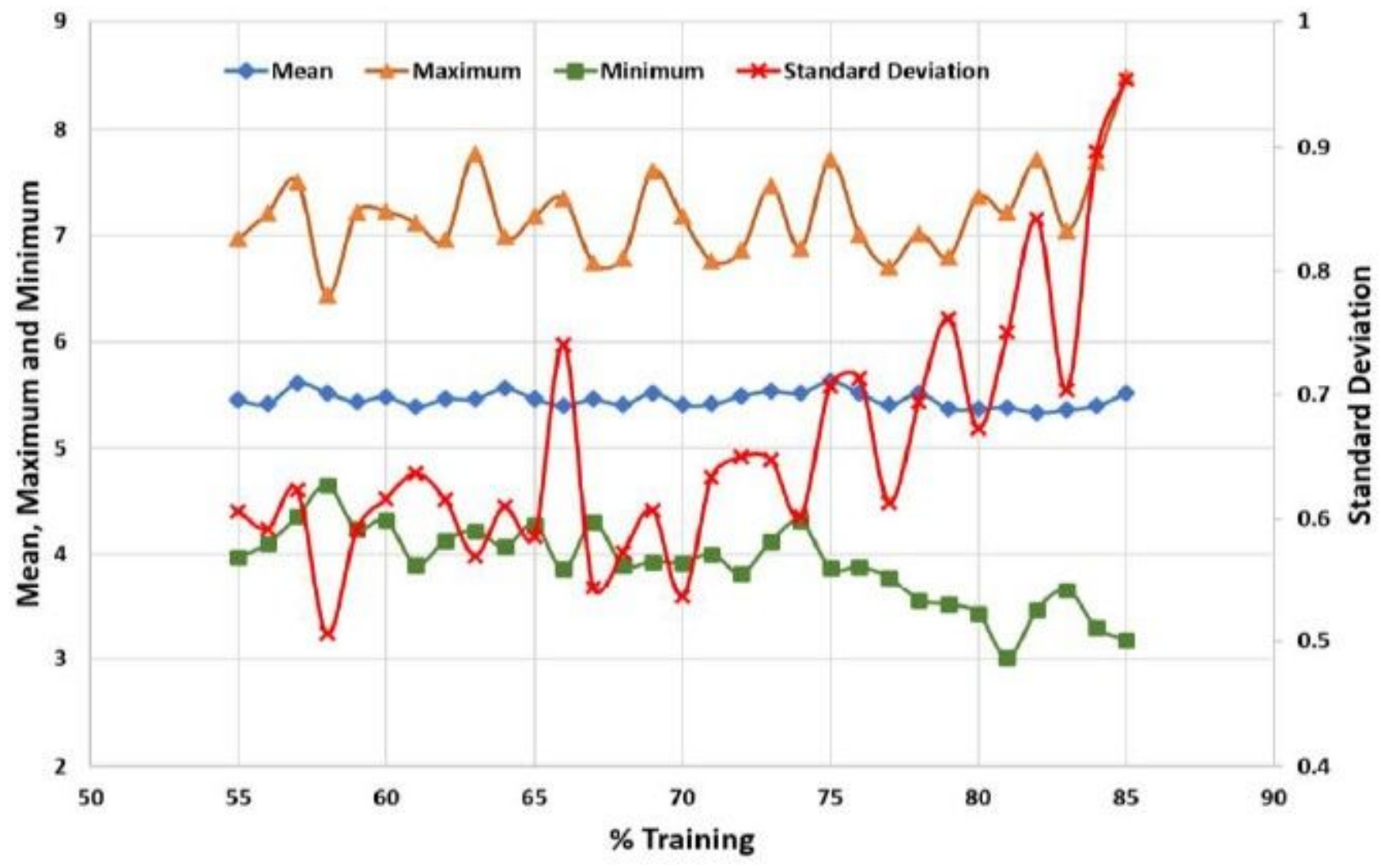

Figure 6

Optimum \% training using $\mathrm{k}$ fold cross-validation method 


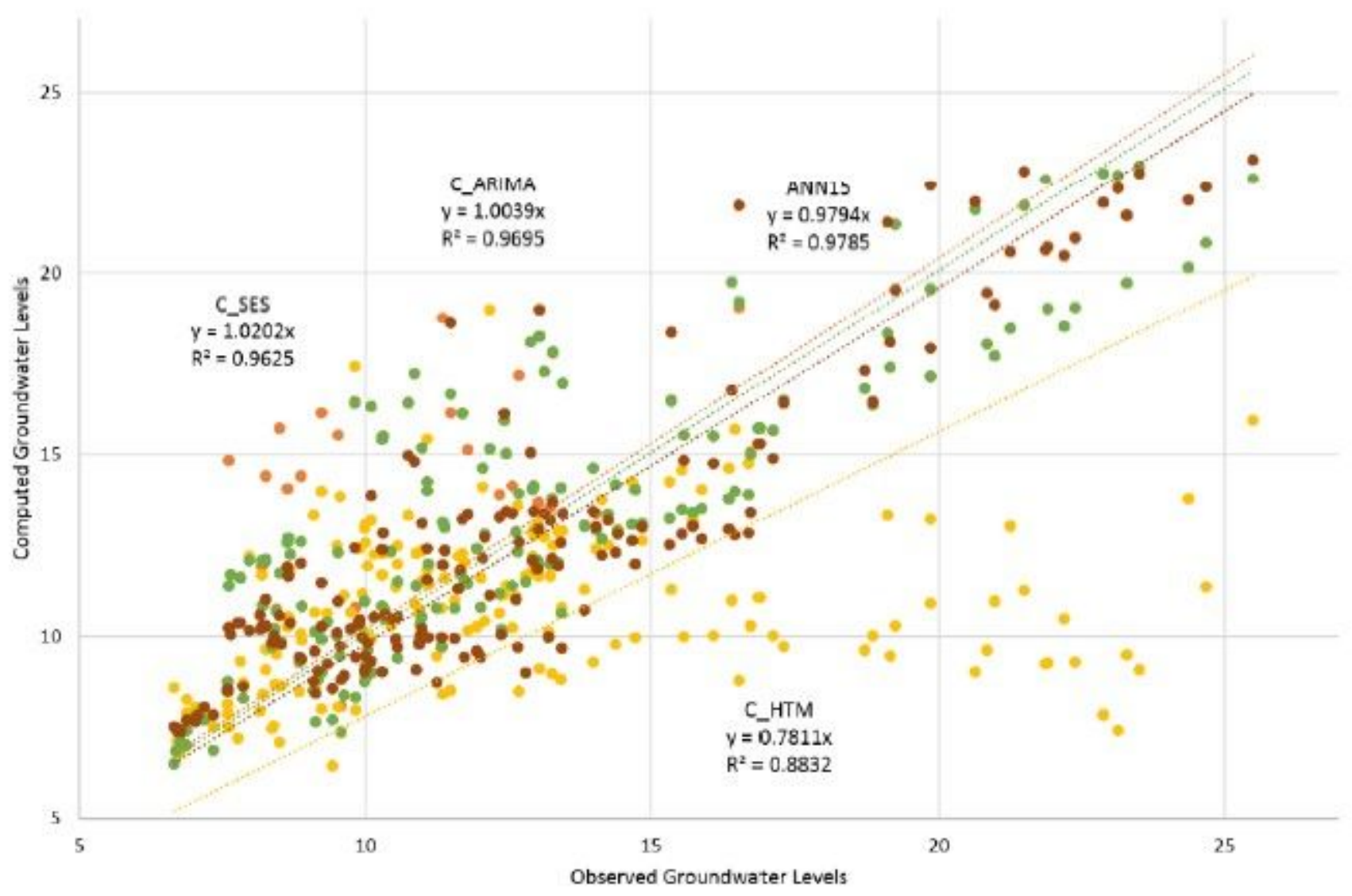

- C_SES * C_HTM - C_Arima - ANN15 …..... Linear (C_SES) …... Linear (C_HTM) ……. Linear (C_Arima) ……. Linear (ANN15)

\section{Figure 7}

Performance of Time series forecasting models and ANN

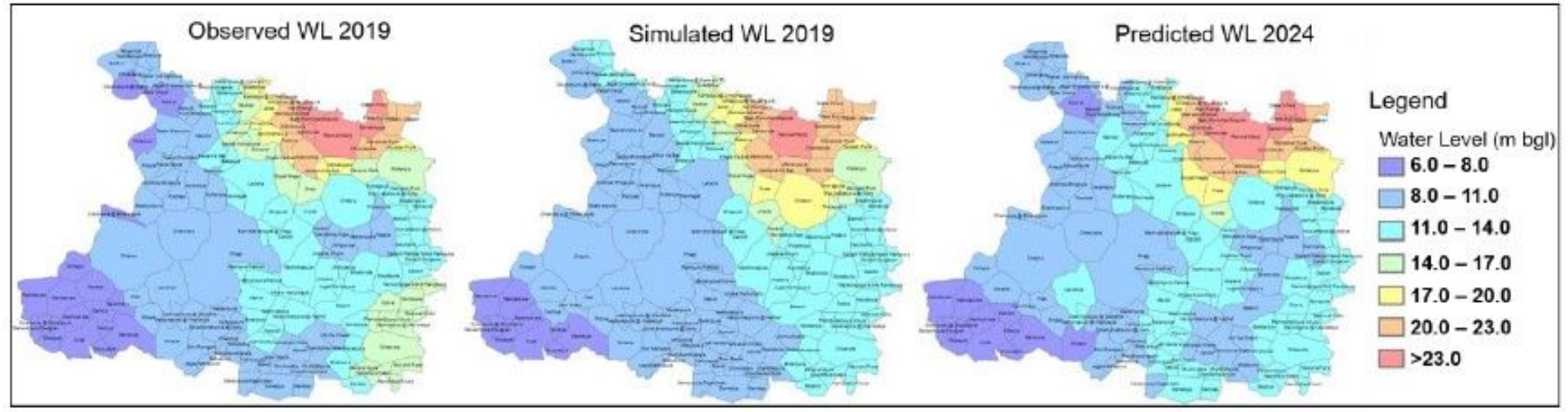

\section{Figure 8}

Observed, simulated and predicted mean values of depth to water level (mbgl) for 2019 and 2024 (premonsoon period) 


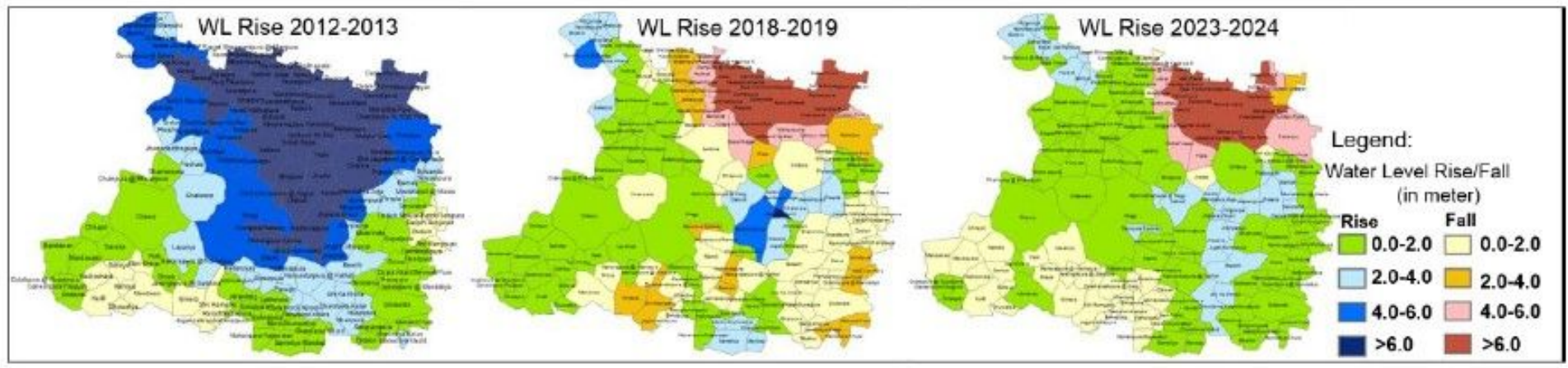

Figure 9

Observed and predicted mean values of water table rise/fall in Phagi tehsil 

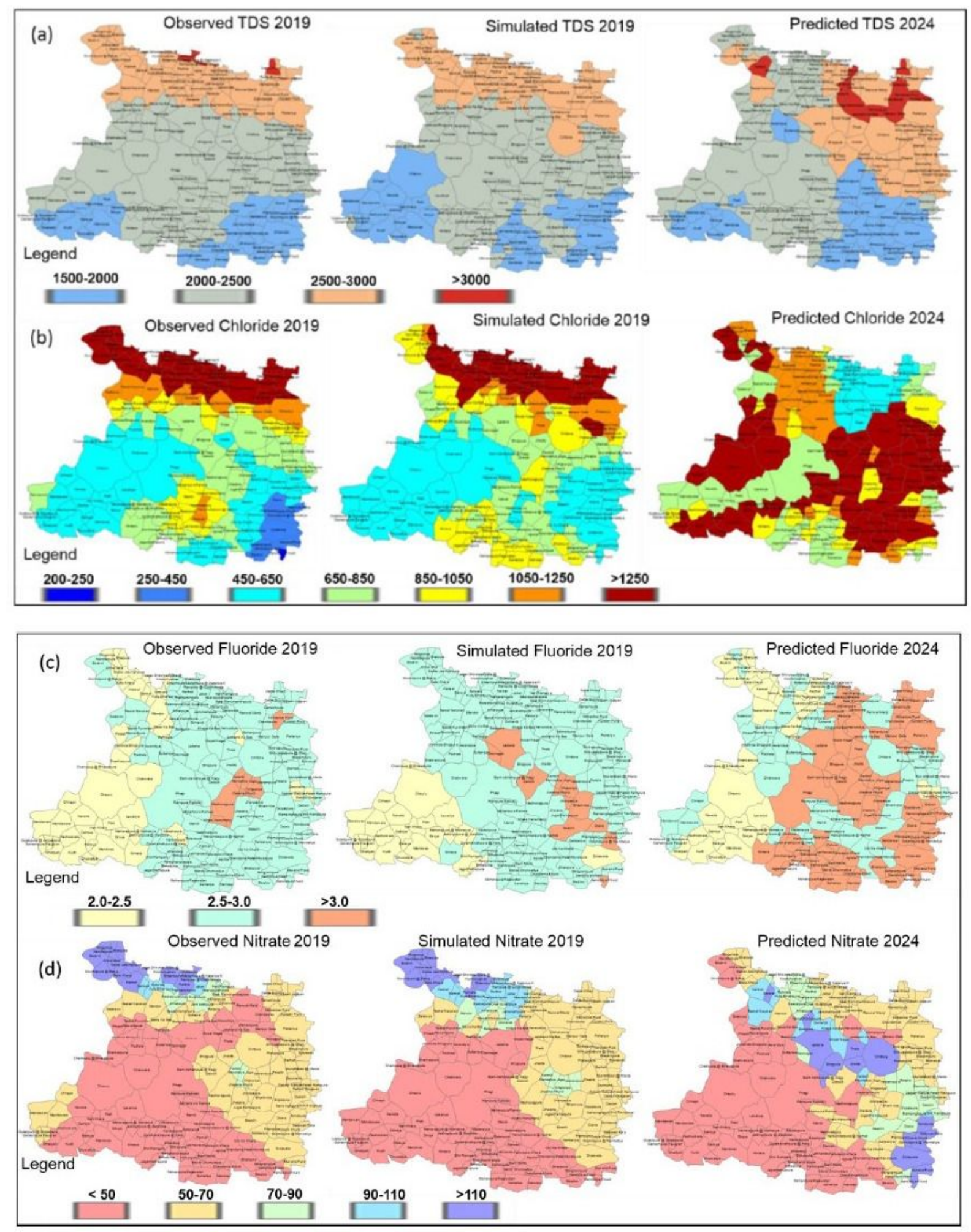

\section{Figure 10}

(a) and (b): Observed, simulated and predicted mean values of TDS and chloride (in $\mathrm{mg} / \mathrm{l}$ ) for 2019 and 2024. (c) and (d): Observed, simulated and predicted mean values of Fluoride and Nitrate (in $\mathrm{mg} / \mathrm{l}$ ) for 2019 and 2024 


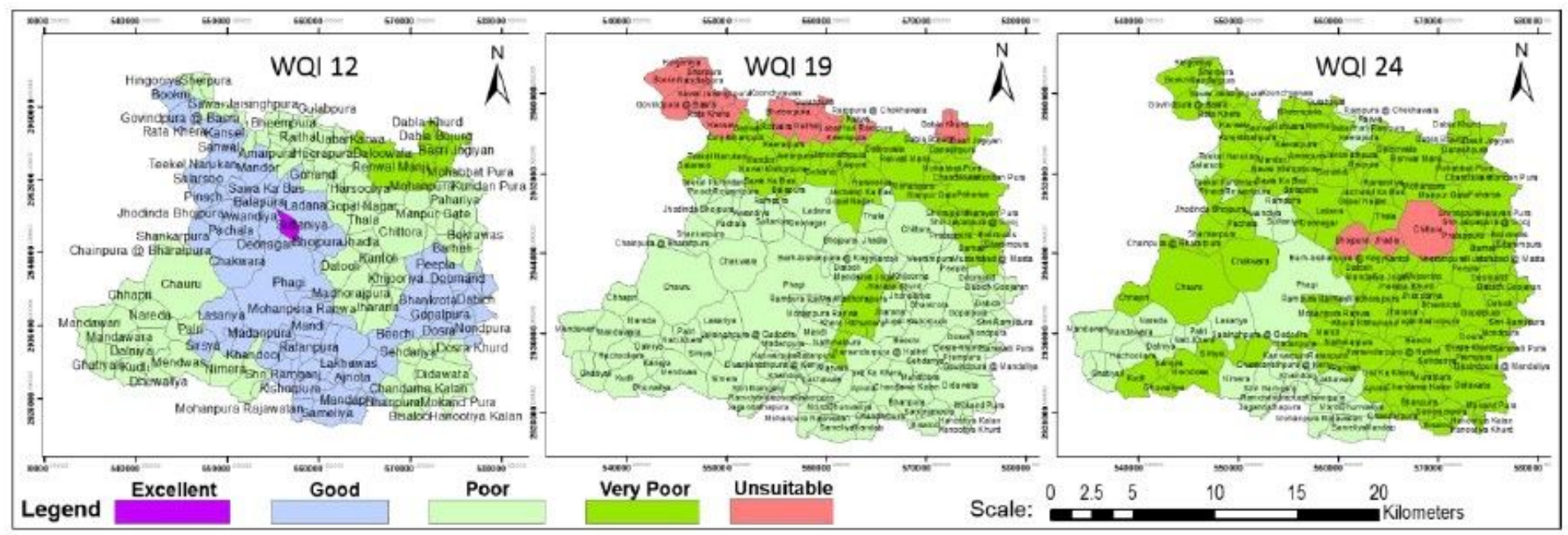

Figure 11

Spatial variations in Water Quality Index (WQI) at village level during 2012-2024 